\title{
MULTIPLE INPUT, SINGLE OUTPUT DC-DC CONVERSION STAGE FOR DC HOUSE
}

\author{
A Thesis \\ presented to
}

The Faculty of California Polytechnic State University, San Luis Obispo

\author{
In Partial Fulfillment \\ of the Requirements for the Degree \\ Masters of Science in Electrical Engineering
}

By

Jason William Baltiérrez

June 2019 
(C) 2019

Jason William Baltiérrez

ALL RIGHTS RESERVED 


\section{COMMITTEE MEMBERSHIP}

TITLE: $\quad$ Multiple Input, Single Output DC-DC

Conversion Stage for DC House

AUTHOR: Jason William Baltiérrez

DATE SUBMITTED: June 2019

COMMITTEE CHAIR: Dr. Taufik,

Electrical Engineering Department

COMMITTEE MEMBER: Dr. Majid Poshtan

Electrical Engineering Department

COMMITTEE MEMBER: Prof. Ali Dehghan Banadaki

Electrical Engineering Department 


\begin{abstract}
Multiple Input, Single Output DC-DC Conversion Stage for DC House Jason William Baltiérrez
\end{abstract}

In this thesis project, a proposed architecture for the multiple input, single output conversion stage for the DC House was designed, simulated, and tested. This architecture allows for multiple different input sources to be used to create a single higher power output source. The design uses a DC-DC boost converter with a parallelable output which has been demonstrated to allow increased total output power as a function of the number of input sources available. The parallelable output has been shown to distribute load amongst the input sources relatively closely to optimize the system. This approach is also desirable since it allows for flexibility in multiple configurations it can be used in. The design was tested using hardware and data results show the performance met and exceeded the needs of the DC House project. Data was taken for configuration with 1, 2, 3, and 4 input sources providing greater than $600 \mathrm{~W}$ of total output power at an efficiency of greater than $92 \%$. This architecture demonstrates the possibility of expanding the total available power for a single output in proportion to the number of available input sources. 


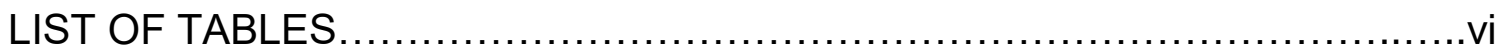

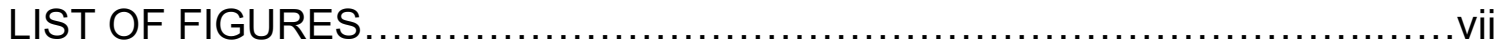

CHAPTER

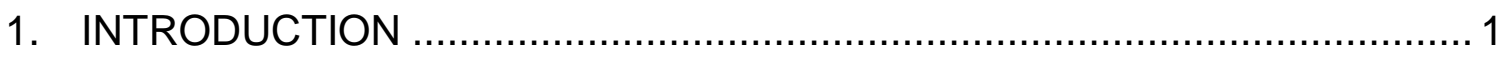

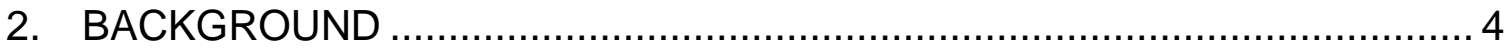

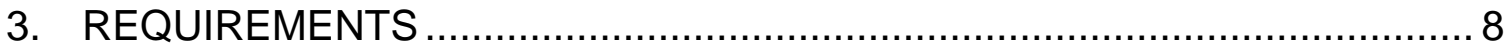

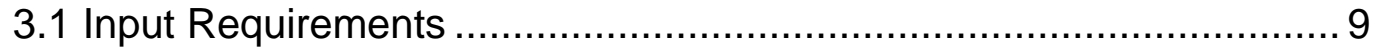

3.2 Output Requirements ……................................................... 9

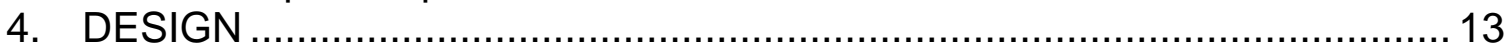

4.1 Design and Considerations. ...................................................... 13

4.2 Calculations, Simulation, and Design ........................................ 19

4.3 Circuit Board Layout ................................................................ 23

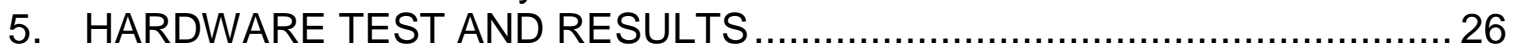

5.1 Initial Testing, Challenges, and Modification .................................. 26

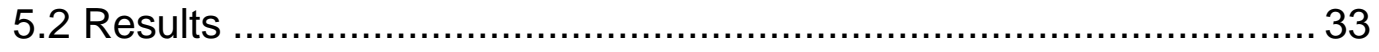

5.2.1 Single Power Supply Performance ................................... 33

5.2.2 Parallel Power Supply Testing ........................................ 38

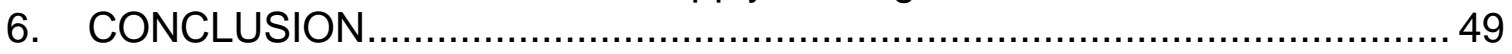

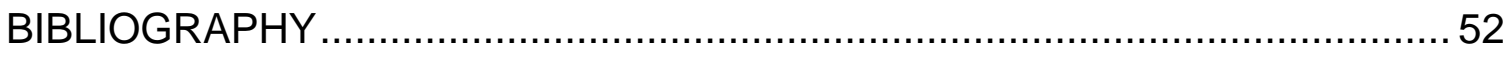

APPENDICES

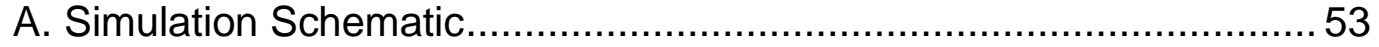

B. Layout Schematic.................................................................... 54

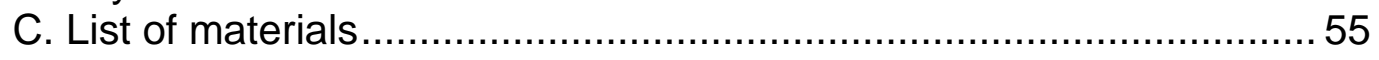

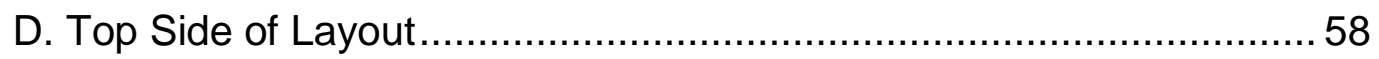

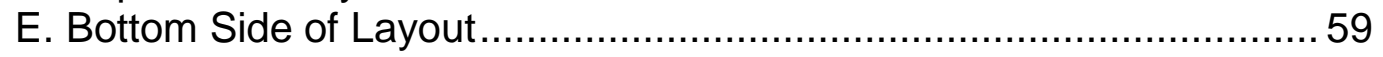




\section{LIST OF TABLES}

Table $\quad$ Page

3-1: Summary of MISO Conversion Stage Requirements ............................... 12

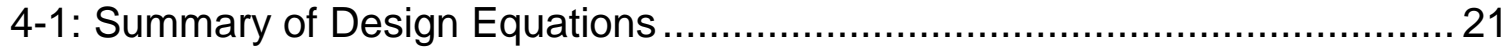

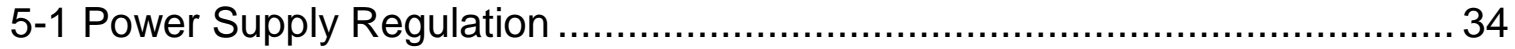

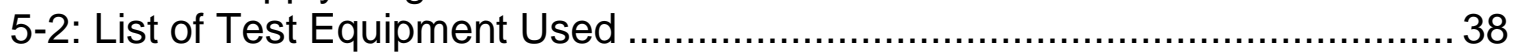




\section{LIST OF FIGURES}

Figure

Page

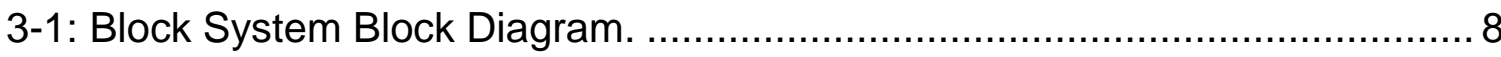

4-1: Feedback Connected to Output after Or-ing Diode .................................. 14

4-2: Feedback Before Or-ing Diode ........................................................ 15

4-3 Voltage Droop Demonstration Circuit .................................................... 16

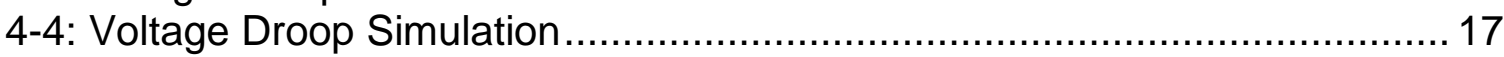

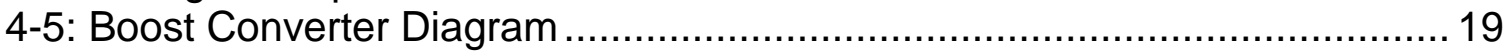

4-6: LTC3814 Boost Controller Functional Diagrams [10] ............................. 20

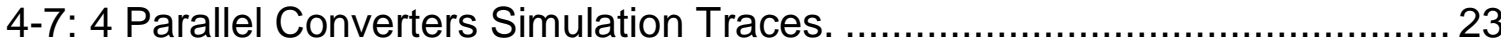

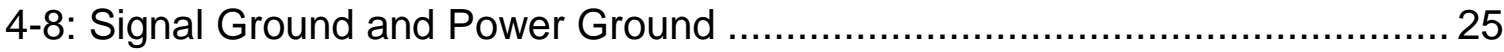

5-1: Configuration for Generating Bias ................................................... 27

5-2 Configuration for Using an External Bias............................................. 27

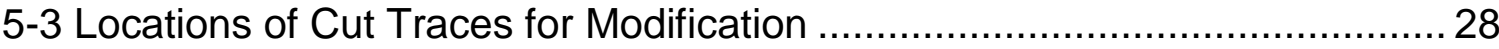

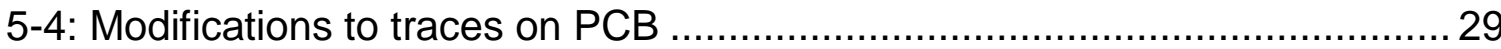

5-5: Completed Modifications for Applying External Bias Voltage ..................... 30

5-6: Completed Converter with Modifications ……......................................... 30

5-7: First Power on Observed Input (Ch. 1) and Output (Ch. 2) ......................... 31

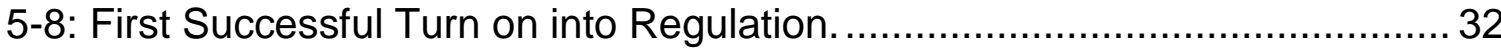

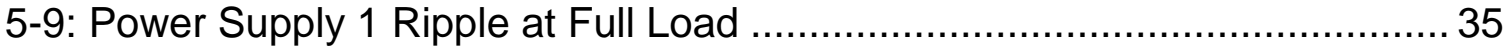

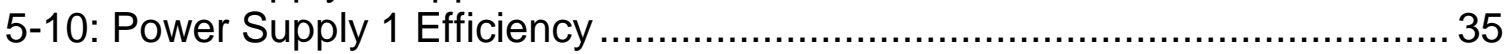

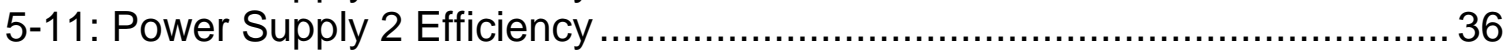

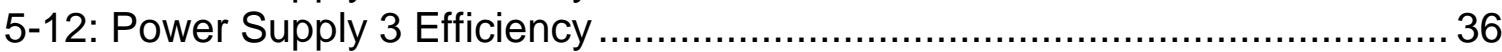

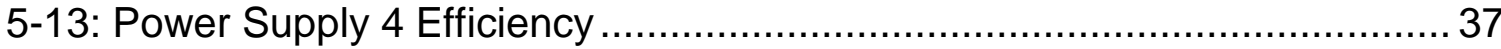

5-14: Power Supply 1 and 2 Load Share Difference.......................................... 39

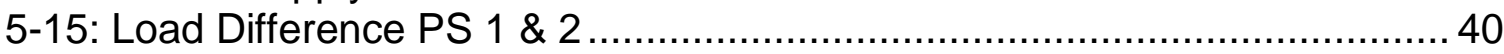

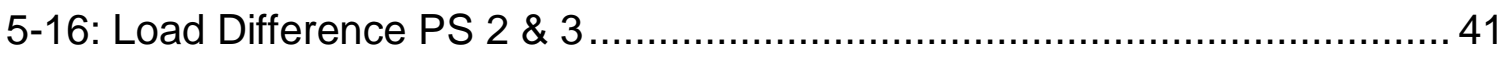

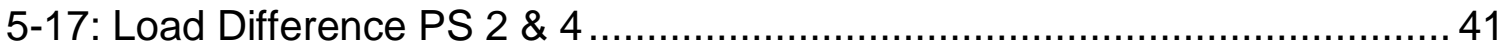

5-18: Worst Case Load Sharing for PS 2, 3, \& 4 ........................................ 42

5-19: Load current of PS 2, 3, \& 4 operating in Parallel................................... 43

5-20: Custom Load Cables ...................................................................... 44

5-21: Block Diagram of Four Paralleled Converters ...................................... 45

5-22: Four Converters Paralleled Testing Setup........................................... 45

5-23: Four Paralleled Converters Shared Load Current .................................. 47

5-24: Worst Case Load Difference of 4 Paralleled Converters......................... 47

5-25 Ripple at 12.8A Total Load Current ........................................................ 48 


\section{Introduction}

It is part of human nature to be curious and learn. This is what sets us apart from the rest of the living organism on Earth, our ability to learn and comprehend. Due to this ability to learn and comprehend we have become the dominant species on earth. Humans use the power of the mind (some more than others) to advance the civilization we have created to new heights. Humans have been able to create tools and machines to create technologies which improve our ability to advance our society. This understanding is creating growth at an exponential rate and is shown through the development of hand tools, animal assisted farming equipment, water mills, wind to drive sailboats, steam power, fossil fuels, and electrical power. In the current era of technological advancement, the forefront driving new technologies is electricity and electronics which drives computing power [1].

The understanding of electricity to potentially do work for humankind began with the understanding and characterization of its properties. In the early $19^{\text {th }}$ century, Michael Faraday contributed to this characterization and was able to demonstrate a simple induction motor. In the late $19^{\text {th }}$ century, contributions from Nikola Tesla and Thomas Edison helped to bring electrical power to the public by developing the first commercially available electrical machines. This was the beginning of electrical power conversion.

When the power of electricity first became available, there was no infrastructure to support it. In the United States, Nikola Tesla was emphasizing the

use of $\mathrm{AC}$ voltage as the primary source of energy transmission. Westinghouse Electric Corporation licensed Nikola Tesla's AC machine designs to setup the first 
long distance transmission lines using high voltage AC between Buffalo and New York [2]. On the other hand, Thomas Edison was promoting his designs which were based on DC voltage distribution. Edison was able to setup DC distribution in New York, but there were limitations to what his machines were able to provide power to. Edison's distribution system initially generated 110V DC but quickly changed to 220V DC so that the line losses could be reduced and cost of copper for distribution could be minimized. Although this was implemented, the serviceable area for electricity distribution was limited to about a single square mile as demonstrated in the Pearl Street Station in New York. Anything requiring higher loads was limited to being in close proximity of the DC distribution center. Inevitably, the AC transmission method gained increased popularity and currently is the main form of distribution across the world [3].

Although DC power was not used for mainstream distribution, DC technology was still advancing in the early $20^{\text {th }}$ century with the development of various devices such as the metal tank rectifier, grid-controlled vacuum-tube rectifier, ignitron, phanotron, and thyratron. These devices are relatively large and it wasn't until the mid $20^{\text {th }}$ century that a new type of technology was created which revolutionized the way DC power could be converted. That technology was the creation of silicon semiconductors and this is the basis for DC electronics as we know today.

With the development of silicon semiconductor devices came many benefits to DC power conversion; the size of DC converters reduced, weight of devices decreased, and the efficiency of conversion increased. Also, new forms of control 
pushed the capabilities of the converters to greater performance. Once these devices became commercially available, they soon made their way into consumer electronics. Power electronics has come to be a mature technology in the last 40 years and can now be found in nearly all machines [4].

The widespread acceptance and integration of power electronics in our daily lives is apparent. Nearly everything needs a charger or needs to be plugged in. With such a high global population, more and more energy is required to keep society moving. Sustainable energy is imperative to ensure earth resources are not depleted. This understanding has led to the steady expansion of the use of clean energy across the United States and the world. With this growth there is the opportunity for technologies that support it to advance and grow. In areas where there is not yet any infrastructure to support mass distribution there is the opportunity to develop a new standard which the developed world has not seen. 


\section{Background}

The United States is a society in which energy is readily available. Energy availability is a necessity to keep this society going and any interruptions of this power could cause issues which is why there is so much investment into the infrastructure. Although this is the case for the United States, there are other parts of the world in which reliable energy is not available. These underdeveloped parts of the world need energy if they are to become integrated into the more advanced societies otherwise the socioeconomic gap will be increased further. The biggest roadblock there is to introduce widespread energy to all is the infrastructure to support it. This includes the equipment for generating energy and also the infrastructure for distribution. There are extremely large startup costs to layout the foundation for delivering energy, especially in rural areas. These costs are something an underdeveloped country cannot support without incurring massive debt. To quickly equip these underdeveloped countries with energy, the startup costs need to be greatly reduced. If the energy is only generated local to the area of need, distribution is greatly reduced.

According to the article "Sustainable energy for developing countries", there are approximately 1.6 billion people across the world who do not have access to basic electrical services [5]. The rural poor in developing countries make up the main population of those without access to electricity. The biggest obstacle for those countries is the financial burden of trying to implement generation and distribution infrastructure. Minimal financial resources from the government also competes with other societal needs such as healthcare. There are minimal needs 
required for energy that could greatly improve the quality of life such as the ability to read at night, pump required drinking water, and listen to radio broadcasts [5].

Focusing on the rural areas for energy distribution, the biggest obstacle to energy availability is the costs [5]. Off-grid applications make the most sense for rural areas since energy generation and distribution can be dispersed local to the area of need without incurring additional costs for long distance distribution. Renewable energy technologies have greatly improved and can provide energy at a lower cost than other options when compared to connecting to the main grid. To combat the fact that renewable energy generation can vary throughout the day depending on the available sources, multiple sources could be used to increase the chance of consistent generation. Furthermore, DC generation is common in renewable energy generation. Maintaining the energy as a DC source instead of creating an $\mathrm{AC}$ source will be more efficient and less complex which will reduce costs and increase reliability. The proposed solution to the worldwide issue is to use multiple renewable energy sources to generate DC electricity for local distribution in rural areas of the world at a minimal cost. This is the basis for the DC House project.

The DC House project will use multiple forms of renewable energy including solar power, hydroelectric power, wind power, and human powered generation [6]. Each of these sources will contribute to the power for the DC house. The purpose of this thesis is to create a method of combining those energy sources for a single distribution source to the house. 
Prior to beginning this project other students have proposed solutions for this main converter, a Multiple-Input Single-Output (MISO) DC-DC converter. Those students proposed using flux-additivity in a multi-winding transformer to combine the energy of the various sources. For these projects, a Flyback converter [7] was used in one case and a Full-bridge converter [8] was used in another case. Under both projects, there were technical issues encountered and the final design was limited in performance mainly in the ability to deliver the desired output power.

For this project, the proposed solution will use an alternate method of conversion than was previously used. The goal is to reduce the risk of creating a converter that only works under certain circumstances. There may be different configurations that this design will be used in so there should be flexibility in the design to accommodate for those different configurations. The end goal is to also minimize costs as much as possible so reducing unnecessary complexities will aid in this effort. This will include minimizing the use of custom components by using off the shelf components readily available to the public.

This project will be to design a single converter which can be paralleled with other copies of the same design. By doing so, it reduces the number of unique components which are used which will reduce the costs. The expectation is that a different number of sources can be used and each one will have its own converter. For any number of converters that are used, they will all have the capability to be paralleled at the output to increase the overall output power capability. Since the design will support energy generation in rural areas which are underdeveloped, the design should be robust and require minimal maintenance. Further details of 
the requirements will be covered in Chapter 3 and the details of the design approach will be covered in Chapter 4. Results of hardware test of the proposed converter will be presented in Chapter 5. Lastly, Chapter 6 summarizes the thesis and discusses further improvements of the proposed converter. 


\section{Requirements}

As stated in Chapter 2, the basis of the project is to take multiple input sources of renewable energy generation and combine them into a single source for the DC House, Multiple Input Single Output (MISO) conversion stage. Each of the input sources should be capable of providing the same amount of maximum power. When all sources are available, the single load (source for the DC House) shall be capable of delivering the max rated power of the combined sources. The output should be a clean source of power providing minimal noise so as to not create issues for the loads. Figure 3-1 shows a block diagram of the system with the item highlighted as the main focus of this design, a conversion stage taking in multiple inputs and producing a single output utilizing a single design, which allows for growth by being parallelable to provide additional power.

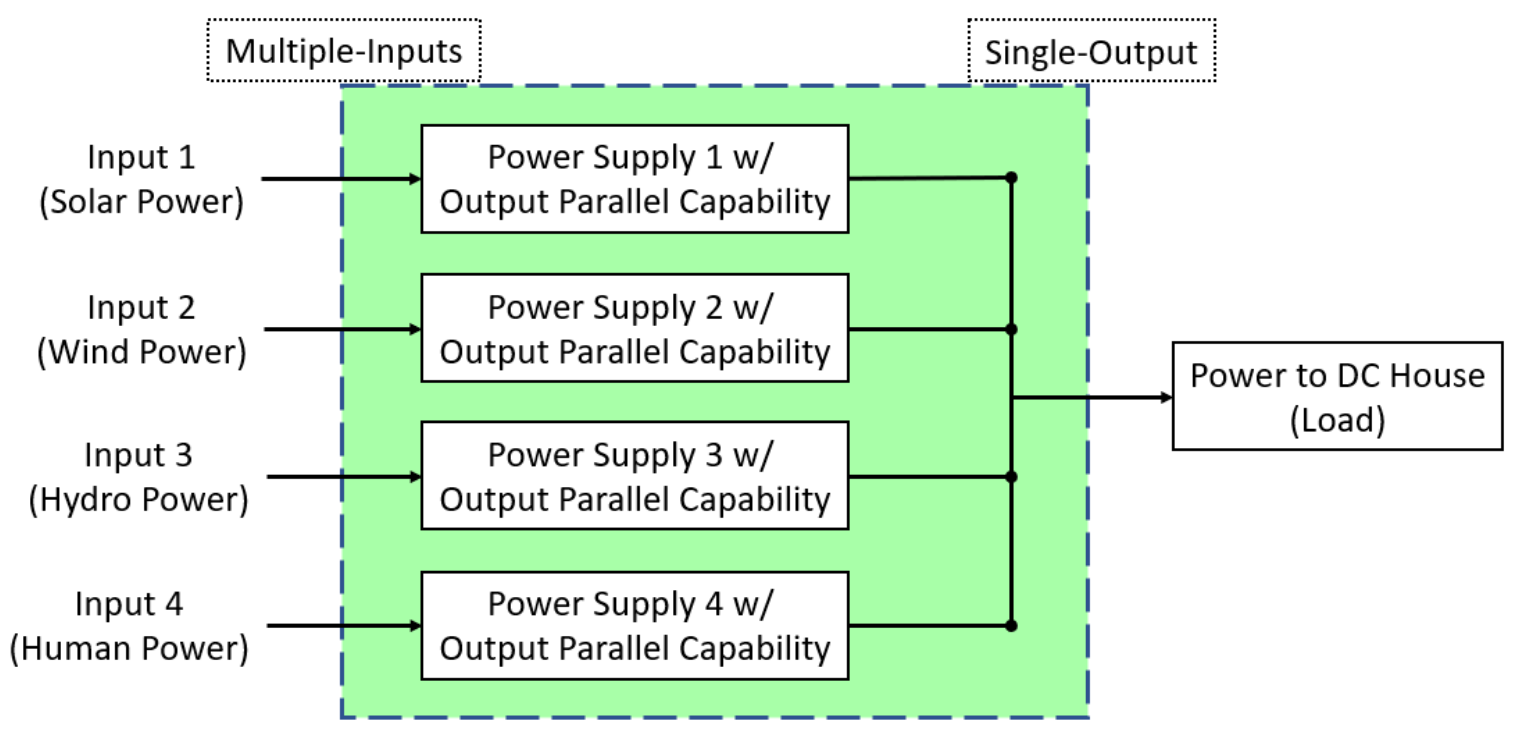

Figure 3-1: Block System Block Diagram. 


\subsection{Input Requirements}

The input source will be generated from one or multiple sources up to 4 sources. Note, these sources are generated using various types of sustainable resources which include harvesting solar energy using photovoltaic solar panels, energy from naturally flowing water using a turbine, harvesting naturally flowing winds using a wind turbine, and a human powered generator. These various forms of generation will be conditioned and will become the sources which provide the input power for the MISO conversion stage.

Each input will have the same requirements. The nominal input voltage of a single source will be 24 Volts. Understanding that there is tolerance on the input voltage regulation of the sources, the parallelable converters should be capable of operating when the input is 24 Volts $+/-2$ Volts. It is also understood that each of the input sources should be capable of supplying a maximum of 200 Watts. This will need to be considered when determining the efficiency of the parallelable converter. When considering worst case conditions, the maximum input voltage is 26 Volts which will be used when considering the voltage rating required for the selected components. For maximum current considerations, one must take into account the minimum operational input voltage which is 22 Volts. From this the maximum average input current is calculated which is about 9.1 Amps.

\subsection{Output Requirements}

The final purpose of the load is to provide a single power source for the DC House. The intended output voltage for this project is a single 48 Volt DC output which is the input for the various devices that will plug into the DC House. So that 
downstream loads can be optimized and sized correctly, the source should have some level of output regulation tolerance. The combined line and load regulations of the output should be $+/-3 \%$ of nominal output voltage. To achieve higher tolerance on output regulation, different circuitry and more precise parts would need to be added. This would increase cost and complexity which is undesirable for the end use of this project. This results in an output voltage range of approximately 46.5 Volts to 49.5 Volts.

To maintain a clean source for the DC house, ripple needs to be minimized to not cause issues with the end load. The goal is to achieve a maximum peak to peak ripple of $2 \%$ of the nominal output voltage. This should be measured when the output is fully loaded and the input is at its nominal of 24 Volts. This indicates a peak to peak ripple of approximately 1 Volt. Voltage ripple on the output of the converter is important for the load it is feeding, depending on the input requirements of the load, various issues can occur if the ripple is too large. Excessive ripple can cause undesirable AC losses, a source of noise which could couple into other circuitry, and excess voltage stress on components.

As previously stated, the maximum input power supplied by each of the sources is 200 Watts. The goal is to be able to provide a maximum power of 600 Watts total when all input sources are available. As a side note, this would indicate that the maximum output current is 12.5 Amps total which should be considered when sizing components. Ultimately, the actual maximum output current would be dependent on the output loading and the efficiency of the converters. If there are a maximum of 4 sources to be used, this would indicate that there is a maximum 
input power of 800 Watts. From this the efficiency of the system can be calculated. With 600 Watts as the maximum output power and 800 Watts as the maximum input power, efficiency of the system should be $75 \%$ at a minimum. As a stretch goal, the system should strive to achieve higher efficiency without incurring significant costs for higher performance components. Higher efficiency improves the performance in multiple ways. Increased efficiency means less wasted power which also means less losses. Less losses means components do not have to dissipate that power so they don't heat up as much, which would stress out the components more. Reduced stress on components increases the reliability of the system so that there are reduced number of failures. In all, this increased robustness essentially produces a system with less failures, which means decreased costs over the lifetime of the system.

Another performance characteristic that should be considered is that all sources might not be available at any given time. So as the number of sources decreases, the maximum output power will also decrease. Since each input is capable of providing 200 Watts and the minimum efficiency is $75 \%$, the total maximum output power capable is limited to 150 Watts multiplied by the number of input sources available, up to four sources. The variability of configurations brings up another point; all the sources are not guaranteed to be available at all times while the system is running. So, any combination of sources could be available and the system should be able to operate under any of those conditions. In other words, for any combination of available sources shown in Figure 3-1, the system should operate at scale to the number of sources available. 
Table 3-1 summarizes the preceding requirements for the multiple-input single-output DC-DC conversion stage consisting of parallelable converters.

Table 3-1: Summary of MISO Conversion Stage Requirements

\begin{tabular}{|l|l|}
\hline Requirements & Value \\
\hline Nominal Input Voltage & $24 \mathrm{~V}$ \\
\hline Input Voltage Tolerance & $+/-2 \mathrm{~V}$ \\
\hline Max Number of Input Sources & 4 \\
\hline Nominal Output Voltage & $48 \mathrm{~V}$ \\
\hline Regulation Tolerance & $+/-3 \%$ \\
\hline Line and Load) & $2 \%$ \\
\hline Maximum Output Voltage Ripple & $600 \mathrm{~W}$ \\
\hline Maximum Output Power & $>75 \%$ \\
\hline Minimum Efficiency at Full Load & \\
\hline
\end{tabular}




\section{Design}

\subsection{Design and Considerations}

The fundamental topology for this design is a boost converter since the voltage is being stepped up from $24 \mathrm{~V}$ to $48 \mathrm{~V}$. The use of a boost converter eliminates the use of a custom transformer and has the potential to have high efficiency. For current sharing, the converters will equip Or-ing diodes to protect one output from damaging the other output when not powered up. Also, each source would have an independent converter which would allow the system approach to have $n+1$ redundancy and expandable. Not only could it accommodate different sources of energy production like wind, solar, hydro, and human power, but if there was an abundance of one resource, there could be multiple instances of that source added to the system. The additional sources could potentially increase the total power capabilities of this conversion stage. Removal of one source should not affect the operation of the others aside from the power capabilities

For this approach, Or-ing diodes will allow the outputs to be tied together and prevent damage caused by back-feeding voltage. One of the limitations of using this approach is the fact that to current share, the output voltages need to be well regulated with a high level of accuracy. I will be using high precision parts to feedback the voltage, but I will also be using an adjustable divider to fine tune the amount of current sharing while the converters are operating in parallel [9].

Since individual converters are being used, each converter has its own sense voltage. The design will allow each source to be independent of one 
another. One case in which this is useful is if one source is available but then another source becomes available while the first source is already regulating. As a real-world example, in the early morning the hydroelectric source could be available and providing power. The sun then rises, and then the solar power source is also available to provide power. The idea is that the second source can come on without interrupting power being provided by the first source. If the sources were both sensing at the point of load, the second source would have trouble bringing up its own output since it would already sense the first sources output voltage which is already in regulation. A simplified schematic of this issue is shown in Figure 4-1.

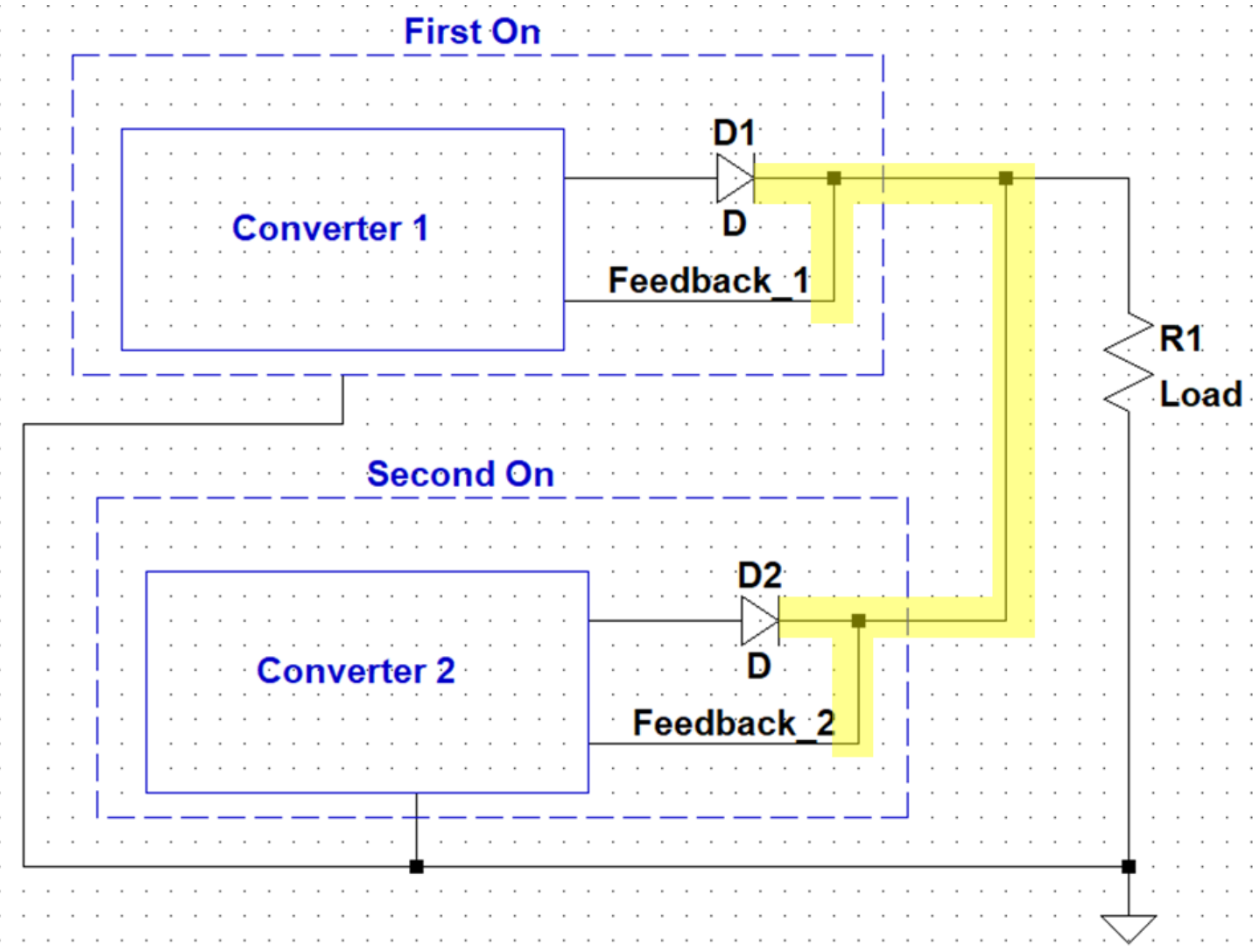

Figure 4-1: Feedback Connected to Output after Or-ing Diode 
To overcome this obstacle, the sensing is performed prior to the Or-ing diode. This way the first converter can be in regulation and the Or-ing diode will block the second converter from sensing the output voltage that is already up. A simplified schematic of this updated configuration is shown in Figure 4-2. It is also important to point out that when fine tuning the output voltage, it will have to be performed under the load range to compensate as best as possible for the voltage drop associated with the Or-ing diode.

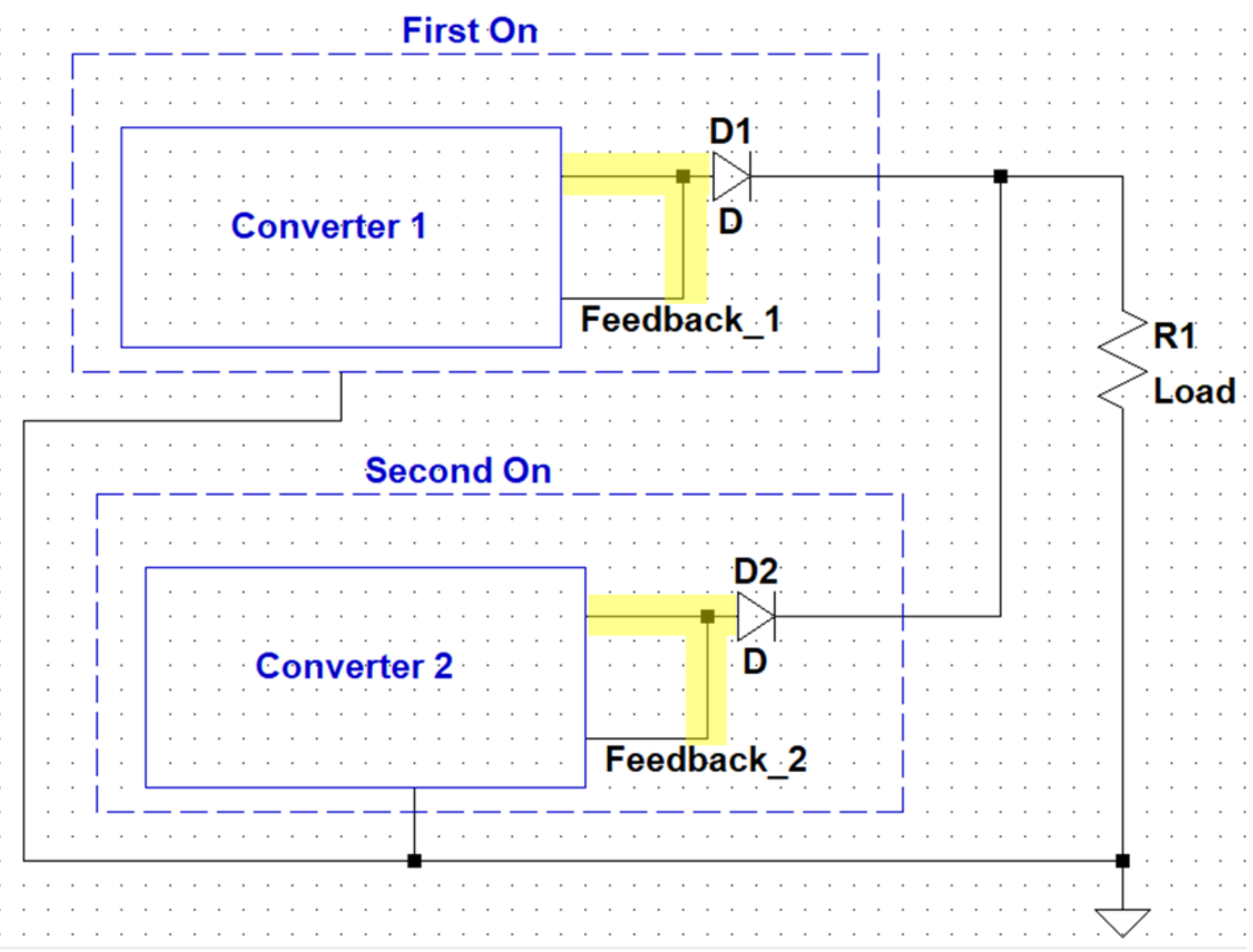

Figure 4-2: Feedback Before Or-ing Diode

For the configuration discussed in the previous paragraph, since the second converter is not providing any current through the load, no current is flowing through the Or-ing diode of that converter. Since current is flowing through the first 
converters Or-ing diode there is a voltage drop associated with it. Since the forward voltage drop across the diode is proportional to the current flowing through the diode there is no voltage drop through the second converter since it is reverse biased as it starts to come up. As the voltage approaches regulation and the voltage on the anode is higher than the cathode, current flow will begin and increase through the diode thus increasing the voltage drop. Note that there are also other voltage drops associated with the various connections and the transmission line. So as the second converter begins to provide current, it reduces the stress on the first converter and theoretically the first converter will provide less current/power. See Figure 4-3 and Figure 4-4 which demonstrates the voltage droop method for current sharing as two sources are applied at different times.

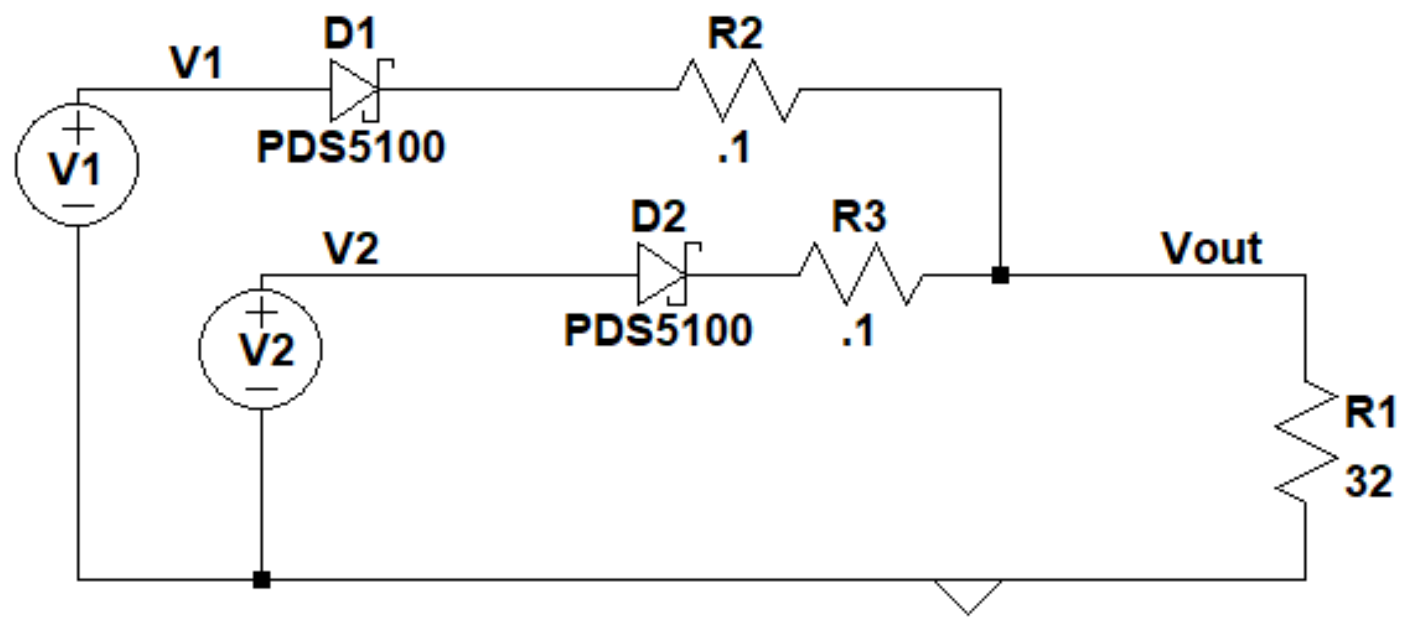

\section{Figure 4-3 Voltage Droop Demonstration Circuit}

Figure $4-3$ is the voltage droop simulation circuit which simulates 2 closely regulating voltage sources coming on at different times. Figure 4-4 shows the traces of each input source, current through each diode, and the total output voltage and current. The traces show that the first source (V1) turns on and 
provides full current to the load R1. Some time later, the second source (V2) turns on and begins to provide current until the sources reach regulation. Once both sources are in regulation, the sources share current as expected.
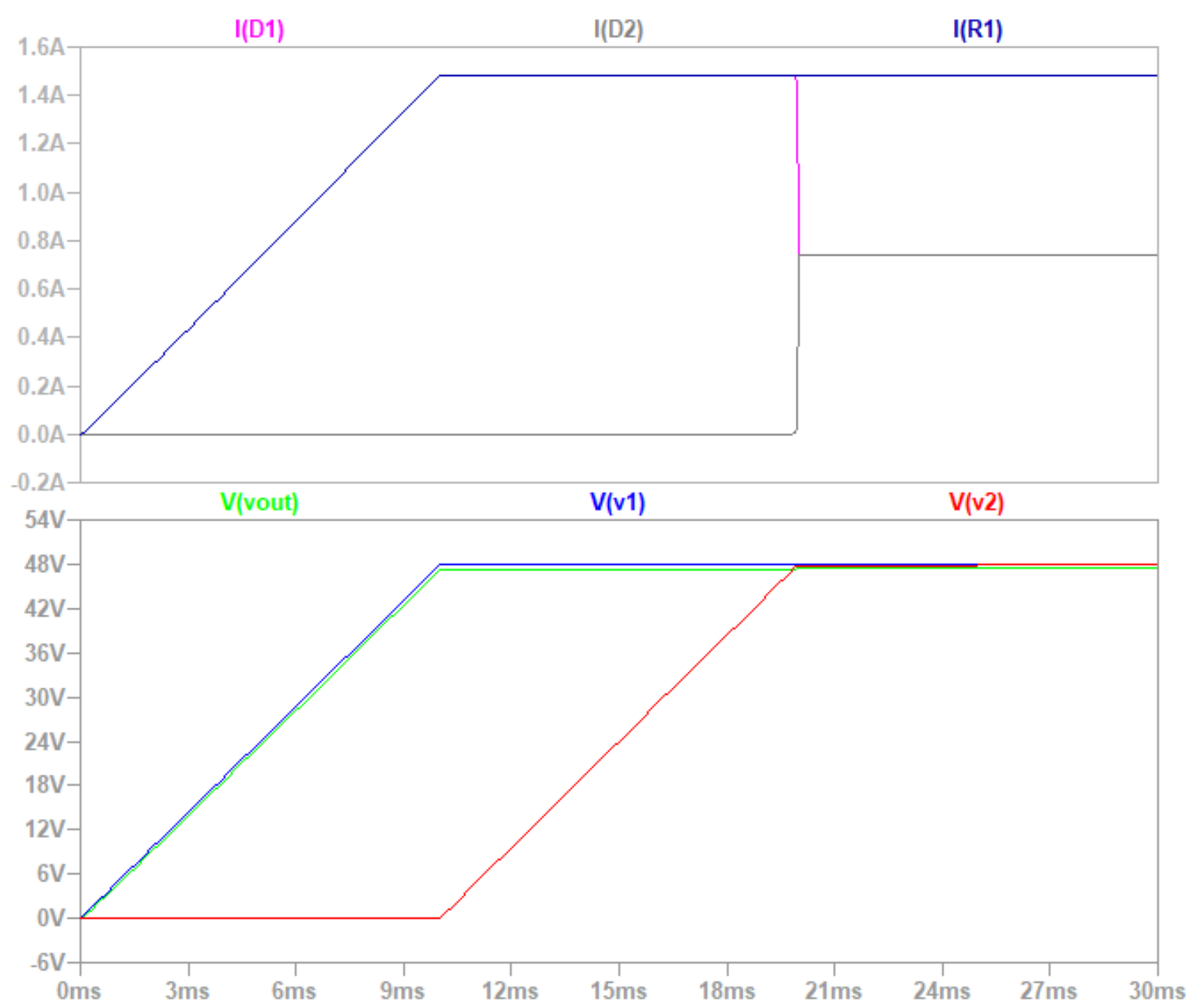

Figure 4-4: Voltage Droop Simulation

This approach of using the parasitic and, potentially intentional, line losses is called the voltage droop method for current sharing. Normally line drops are considered undesirable in a power converter since they contribute to losses. In this case they are beneficial to a certain extent because this inherently provides current sharing [9]. 
To increase the converters robustness and prevent it from operating in conditions it was not intended for, some additional circuitry was added. There is an under-voltage lockout circuit that prevents the converter from switching until the allowable input voltage is reached. This is to prevent any peak currents from flowing when the input voltage is low. There is also a circuit that monitors the bulk capacitors near the output to ensure the voltage has been charged to the good input voltage range. Once both parameters have been fulfilled, the circuitry allows the converter to begin switching by releasing the Run/Soft Start pin. In both circuits, hysteresis was also added to prevent the circuit from getting stuck in a 'hiccup' mode. This is when the circuit is enabled and begins to draw large currents which causes a voltage drop at the sensed voltage which falls below the minimum enable voltage which shuts off the converter. The input then rises again since there is no current draw and passes the enable threshold which starts the process over again. Hysteresis adjusts the enable threshold to a lower threshold once the upper threshold is passed. This allows the input to fall slightly then continue to rise as long as it doesn't reach the lower threshold.

Since the point of regulation is prior to an Or-ing diode, there is increased variability of the regulation voltage after the Or-ing diode due to variances in the voltage drop of that diode. This applies to both variability from component-tocomponent and over the load range since the voltage drop across a diode changes as a function of load. In order to compensate for the amount of variability there can be of the regulation voltage, a potentiometer was used in the output voltage 
setpoint resistor divider. This allows the output voltage to be fine-tuned to allow the most balanced current sharing between converters.

\subsection{Calculations, Simulation, and Design}

The boost converter is the fundamental topology used for this project. A simplified diagram is shown in Figure 4-5.

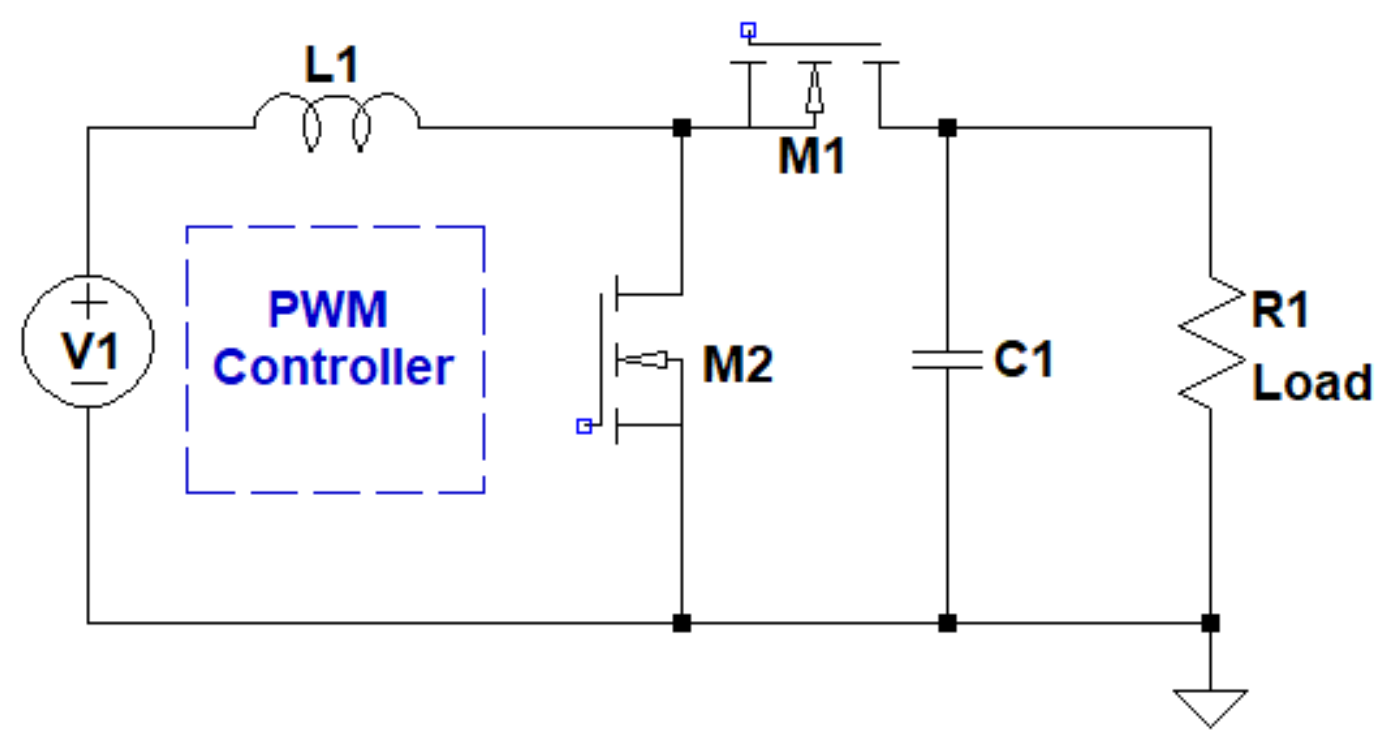

Figure 4-5: Boost Converter Diagram

When designing a boost converter, the critical components of the design are the inductor, switches, and the controller. Normally, a diode would be used in place of M1, shown in Figure 4-5, but in this case using a MOSFET decreases the losses and increases the efficiency.

To effectively control the timing of both switches, a controller was chosen which specifically has this functionality. If a standard PWM controller was used and the single driver was used to drive the MOSFET's inversely of each other, you could potentially short the output if both switches were conducting at the same 
time. This is due to the fact that MOSFET's have parasitic elements and there are limitations to gate drivers which do not allow the MOSFET's to turn on and off instantaneously. Therefore, there needs to be a small amount of dead time (delay) to allow one switch to turn off and the other to turn on. The controller that was chosen to regulate this converter is the LTC3814. A functional block diagram of this controller is shown in Figure 4-6 [10].

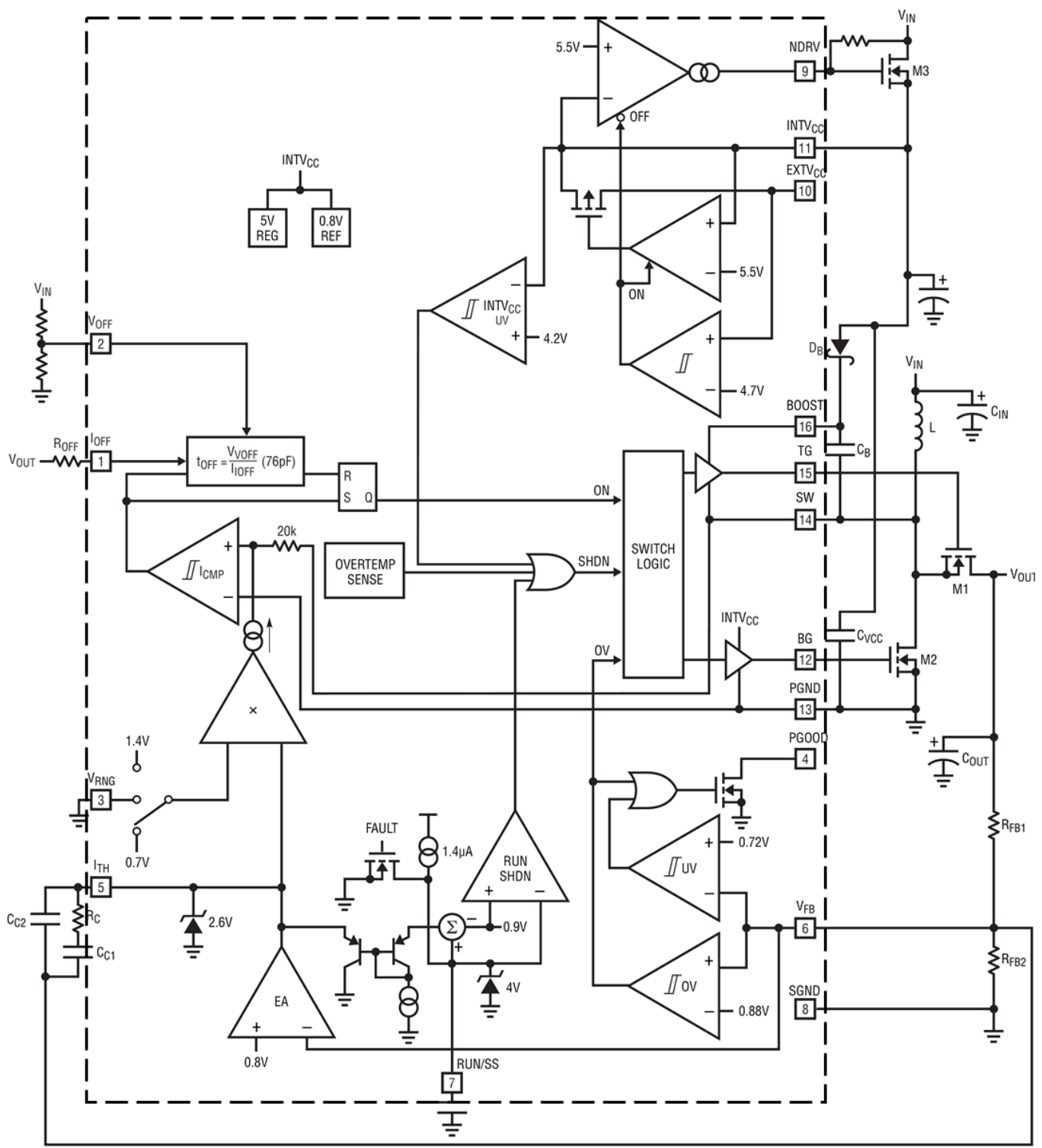

Figure 4-6: LTC3814 Boost Controller Functional Diagrams [10] 
The MOSFET which replaces the diode is known as a synchronous MOSFET. Since the synchronous MOSFET could be conducting through the body diode during the dead time before it is commanded to turn on, the LTC3814 datasheet recommends using a diode in parallel with the MOSFET. Current will flow through this alternate diode instead of the body diode only if the diode is chosen correctly by having a lower forward voltage drop. This provides the benefit of lower losses during that transition and also distributes losses amongst other components which reduces stress on those components.

When designing the Boost converter, worst case conditions are considered. The highest currents occur when the input voltage is at a minimum. For this design, the minimum operational input voltage used in the design equations was $20 \mathrm{~V}$ which provides additional margin since the required minimum operational input voltage is $22 \mathrm{~V}$. Table $4-1$ shows a summary of the design equations used for the fundamental power components. These equations were placed in an Excel sheet to allow easy manipulation of variables. These equations were taken from both the LTC3814 [10] datasheet and book "Power Electronics" by Muhammad H. Rashid [4]. There were also component values specific to the LTC3814 which were considered for choosing components. This included items like Soft Start capacitance for controlling the ramp on rate of the output which.

Table 4-1: Summary of Design Equations

\begin{tabular}{|c|c|c|}
\hline Variable & Equation & Value \\
\hline $\begin{array}{c}\text { Duty Cycle } \\
\left(\mathrm{D}_{\max }\right)\end{array}$ & $1-\frac{\left(\text { Vin }_{\text {minimum }} * \text { efficiency }\right)}{\text { Vout }}$ & .6875 \\
\hline $\begin{array}{c}\text { Inductor Average Current } \\
(\text { lavg })\end{array}$ & $\frac{I_{\text {out }}}{\left(1-D_{-} \text {max }\right)}$ & $10 \mathrm{~A}$ \\
\hline
\end{tabular}




\begin{tabular}{|c|c|c|}
\hline $\begin{array}{c}\text { Inductor Current Ripple } \\
(\text { Iriple })\end{array}$ & Percent $_{\text {ripple }} * \frac{I_{\text {out }}}{\left(1-D_{\text {max }}\right)}$ & $2 \mathrm{~A}$ \\
\hline Minimum Inductance $\left(\mathrm{L}_{\text {min })}\right.$ & $\frac{\left(\text { Vin }_{\text {minimum }} *\left(\text { Vout }- \text { Vin }_{\text {minimum })}\right)\right.}{\left(I_{\text {Ripple }} * f_{\text {switching }} * \text { Vout }\right)}$ & $18.7 \mu \mathrm{H}$ \\
\hline $\begin{array}{c}\text { Inductor Peak Current } \\
\left(\text { I }_{\text {peak }}\right)\end{array}$ & $\frac{I_{\text {Ripple }}}{2}+\frac{I_{\text {out }}}{\left(1-D_{\text {max }}\right)}$ & $11 \mathrm{~A}$ \\
\hline
\end{tabular}

Once the fundamental component values were chosen, the circuit was simulated using LTspice ${ }^{\circledR}$. The simulation program has a model for the controller being used so the simulations greatly reduce the risk of the design. Initially, a single converter was simulated to ensure the fundamental design was operating as planned. The circuit was simulated under various conditions including various loading conditions and input voltage conditions. Once the fundamental design was operating as planned, additional copies of the circuit were inserted, and the design was simulated while paralleling converters. The simulated schematic is shown in Appendix A. Figure 4-7 shows various traces of the simulation. For this simulation, the input sources were set to different levels and also turned on at different times/ramp on rates. The output voltage traces, both shared and individual voltages before the Or-ing diode, were monitored to validate all converters were in operation. Each of the converters output voltage setpoints were varied slightly and the individual output currents were monitored. Once all the individual converters were in regulation, the load current was increased up to full load of $12.8 \mathrm{~A}$. It can be seen that the individual converters share load current during the simulation. 


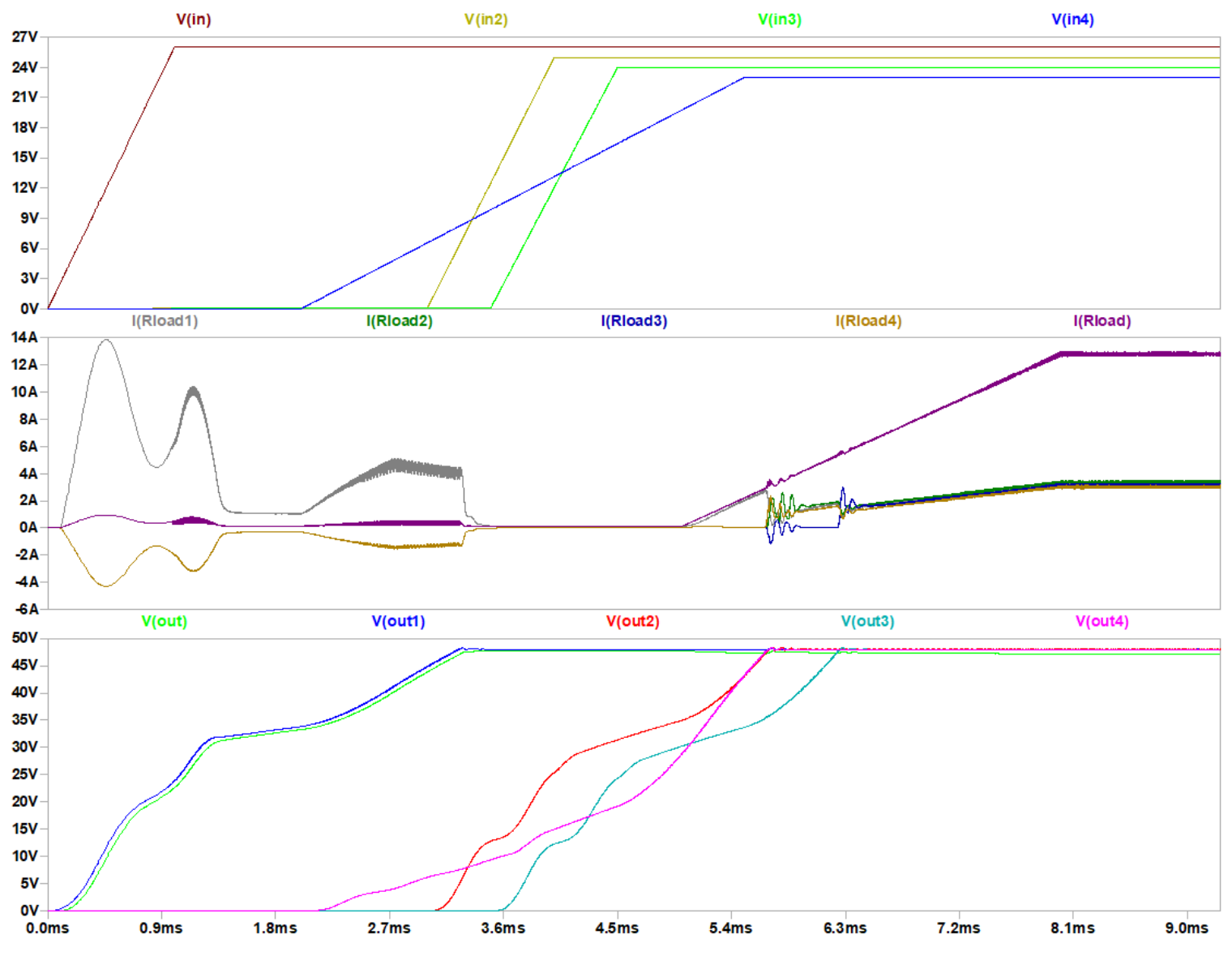

Figure 4-7: 4 Parallel Converters Simulation Traces.

\subsection{Circuit Board Layout}

As previously stated in Section 4.2, the design was initially simulated using LTspice $₫$ to gain confidence in the fundamental performance of the design. Real components found mostly on https://www.digikey.com/, were put in a list linked to the reference designators on the simulation schematic and would eventually be purchased. Prior to purchasing, the simulation components were modelled as closely as possible to the actual components that were to be used. This was to verify that the component parasitic elements would not make a significant difference in the performance of the converters. This schematic was then imported into the printed circuit board (PCB) creation software, EAGLE. The final schematic 
used in layout is shown in Appendix B. Some components did not use standard packages from the EAGLE component library, so those component pad and layout information had to be created manually based on the datasheet. A final list of material purchased is shown in Appendix C.

The layout of the printed circuit board was done in the free version of EAGLE. The overall flow of the power supply was generally laid out to support the direct current flow and minimize impedance to create an efficient path. The PCB is a two-sided PCB which allowed placement of components on both sides of the PCB. Two sides allowed for components to be tightly coupled such as placing capacitors near IC's for high frequency decoupling. Care was taken to reduce noise from coupling onto control signals which could be noise sensitive. Noise is caused by high $\mathrm{dv} / \mathrm{dt}$ and di/dt components and traces. It is coupled onto these signals through parasitic paths created within the layout. In order to avoid coupling noise onto these sensitive signals and components, parasitic paths were reduced as much as possible. One method is to use an analog-signal ground to isolate noisy signals from noise sensitive signals. This is a plane that sits directly underneath the noise sensitive components. See Figure 4-8 for this portion of the PCB layout. There is only one location where this ground is connected to the main power return. This is to keep noisy return currents from passing through this portion of the ground plane [10]. The complete layout is shown in Appendix D and E. The PCB's were purchased from the company Oshpark, (https://oshpark.com/). 


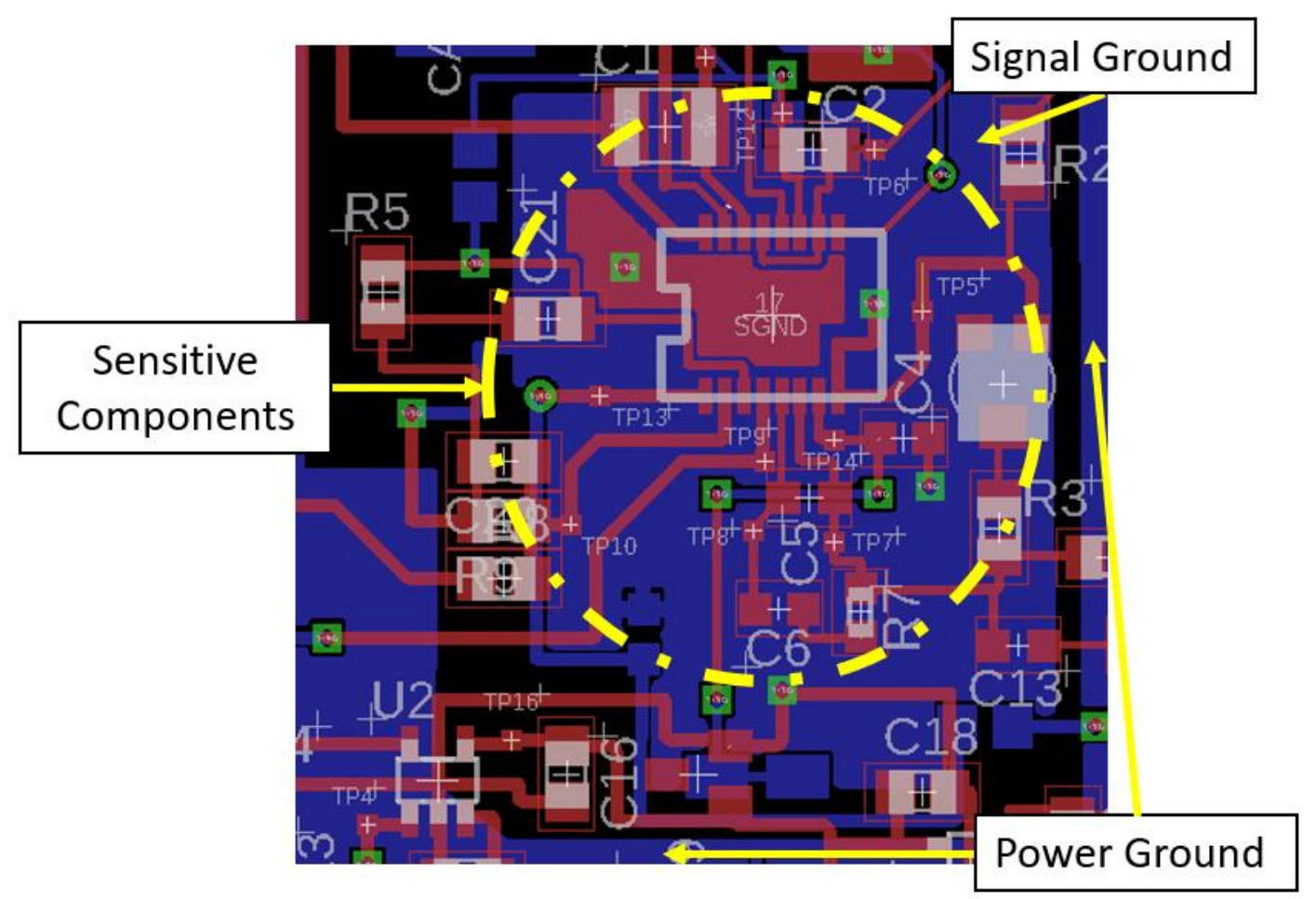

Figure 4-8: Signal Ground and Power Ground 


\section{Hardware Test and Results}

\subsection{Initial Testing, Challenges, and Modification}

When initially testing, during first power on, it is important to be on the cautious side and assume that something could be incorrect. It could be something as simple as an incorrect connection, configuration of instrumentation like power supply set for abnormal source voltage, incorrect component, or many other potential hazards when it comes to developing a new design. Prior to applying any power, general PCB and component checkout should be performed. Continuity checks should also be performed in order to verify proper connections are made and there are no errors from the PCB manufacturer. If possible, portions of the circuit should be powered on individually to verify functionality prior to operating the entire system. If a portion of the circuit is not operating correctly, the hope would be to identify the issue and resolve prior to power up the entire system. When initially powering on, the setup should be double checked. Once this is done, the input current should be set relatively low and the source voltage should be set to zero volts. Slowly ramping up the source voltage allows you to monitor the input current for abnormal current draw. Once this is done, it is best to turn on the source voltage as it was intended to be done so that the circuit can operate in its intended configuration.

During initial checkout and verification, it was noticed that the drive voltage to the Power MOSFET's was low, approximately 5.5V. For logic level MOSFET's, this would be sufficient. For the MOSFET's used in the design, this drive voltage was not sufficient to fully enhance the MOSFET. MOSFET's that are not fully 
enhanced have increased on state resistance and will increase losses in the converter. Luckily, the design could be modified to drive the MOSFET's at a higher voltage. The configuration in Figure 5-1 (the original configuration) would need to be connected as shown in Figure 5-2 [10]. As you can see, this included connecting NDRV, INTVcc, and EXTVcc pins together as well as bringing in an external bias. To achieve this, the EXTVcc pin needed to be disconnected from ground and the NDRV MOSFET and Resistor shown in Figure 5-1 were removed.

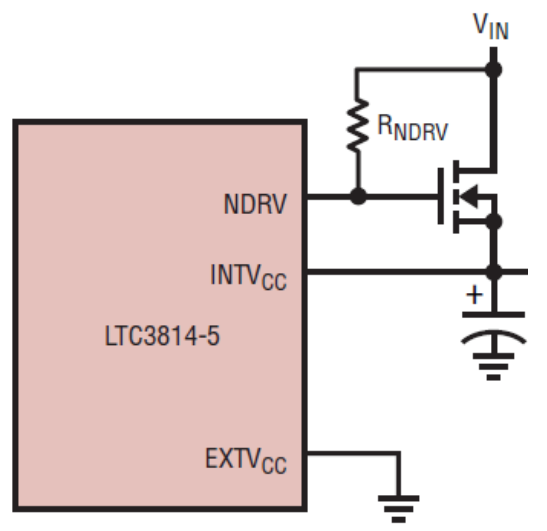

Figure 5-1: Configuration for Generating Bias

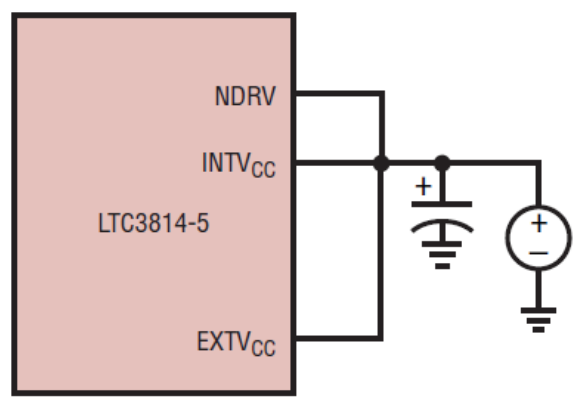

Figure 5-2 Configuration for Using an External Bias 
Making the modifications outlined in the previous paragraph are straight forward from an electrical standpoint, but from a physical standpoint, it was difficult. Two traces needed to be cut (shown in Figure 5-3), components removed, and two jumpers were needed. The biggest issue was with one of the cuts. It ran underneath the LTC3814 controller which meant that the controller needed to be de-soldered, the trace could then be cut, and the controller could afterward be resoldered.

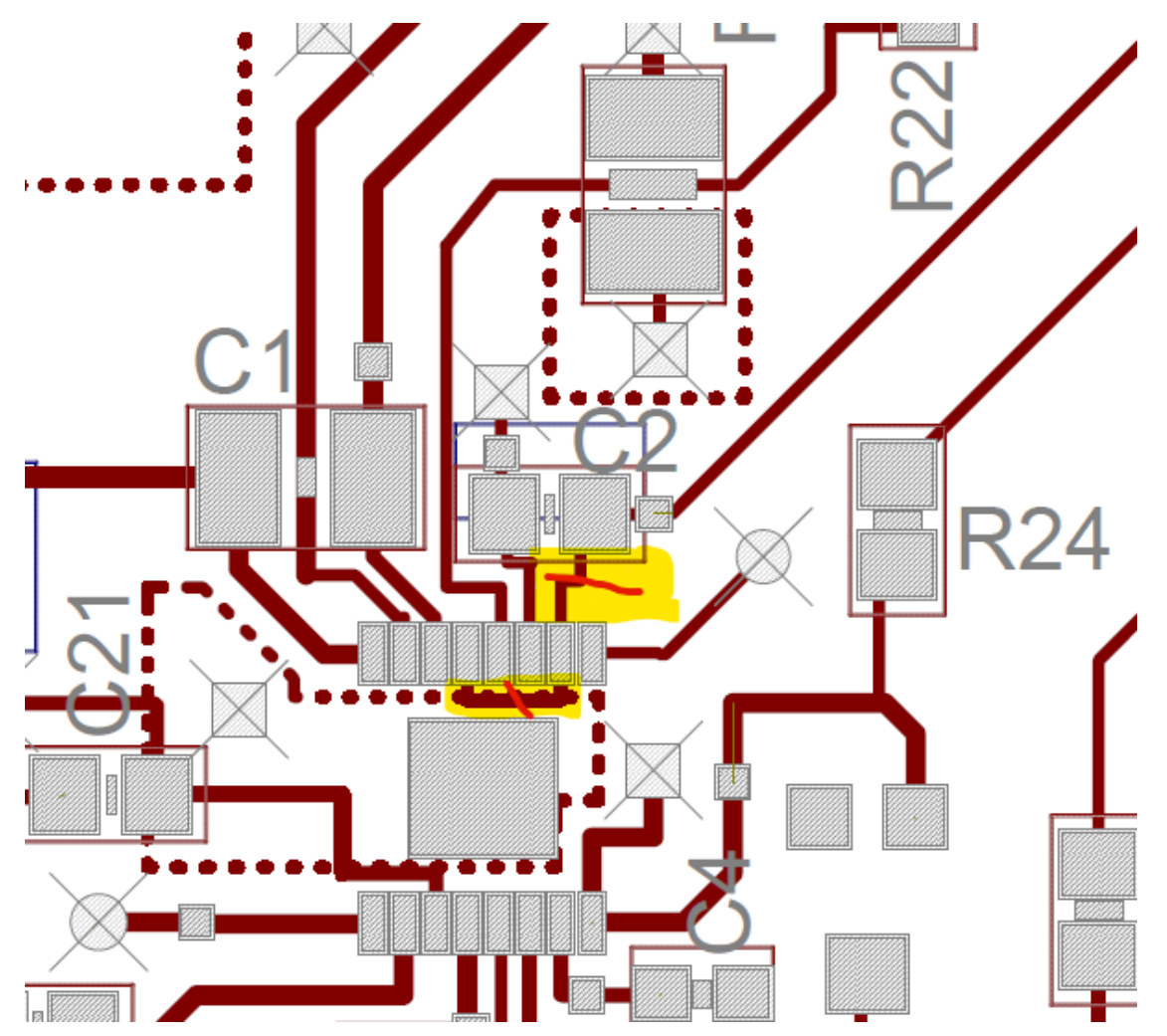

Figure 5-3 Locations of Cut Traces for Modification

Removing the controller was only necessary for the first unit since it was built and tested prior to any other converters being built. The following units had the modifications done before soldering on the controller. The cut traces are shown in Figure 5-4. 


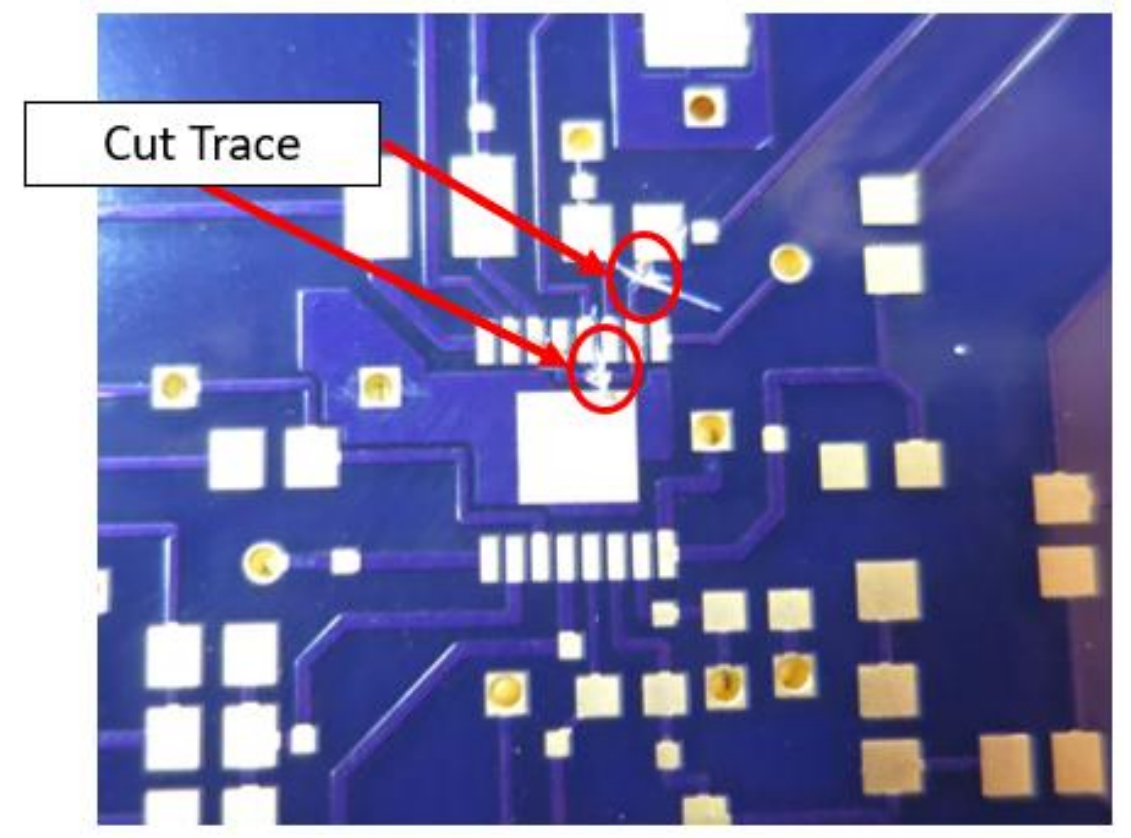

Figure 5-4: Modifications to traces on РСВ

In addition to the modifications of the circuit components and PCB modification, there was also the need to apply an external bias to the chip. This voltage was chosen so that the MOSFET's could be fully enhanced and provide the lowest on state resistance. Driving the gate to $10 \mathrm{~V}$ was sufficient to fully enhance the MOSFET according to the datasheet. In order to apply the voltage to the circuit, wires were soldered to the appropriate nets. The modified circuit with bias wires is shown in Figure 5-5. Once these modifications were made, the unit could be tested and data could be collected. A completed converter with modifications is shown in Figure 5-6. 


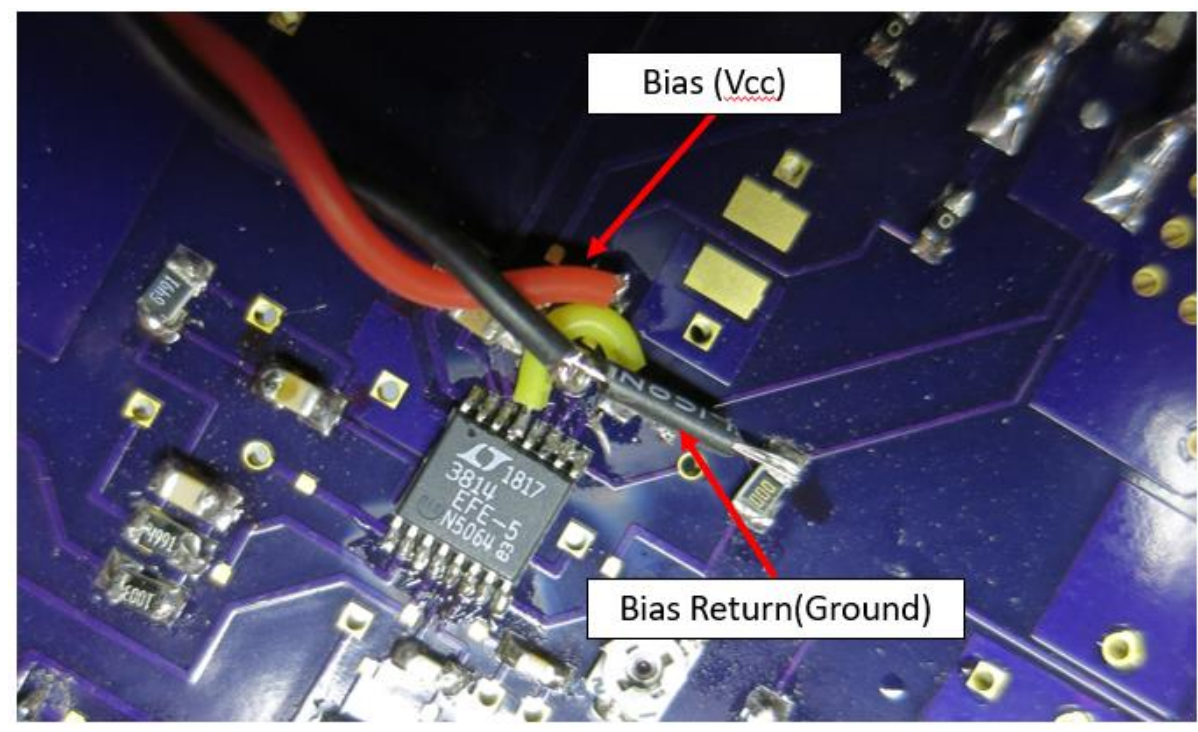

Figure 5-5: Completed Modifications for Applying External Bias Voltage

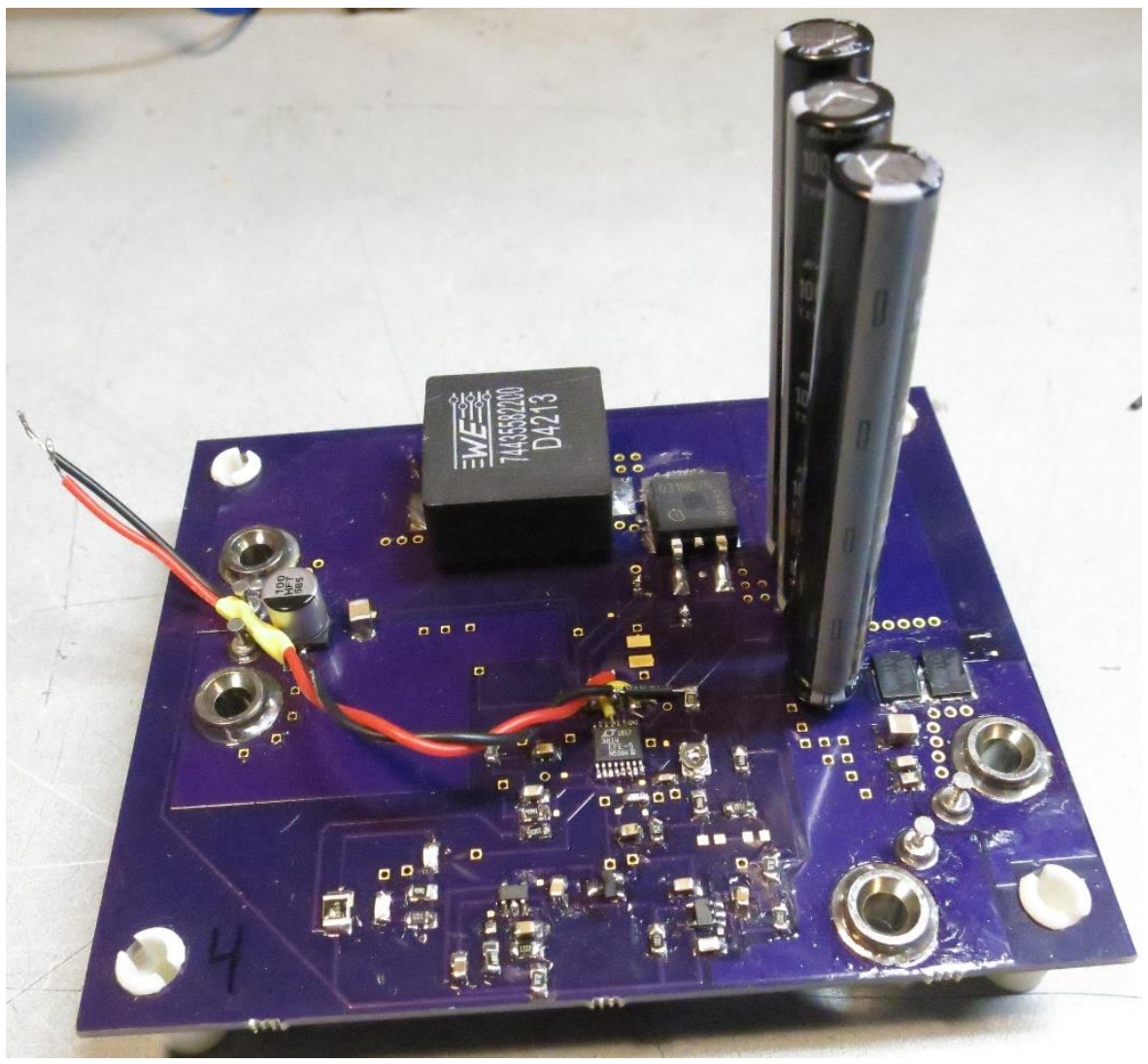

Figure 5-6: Completed Converter with Modifications 
During first power on into regulation, it initially appeared as if the converter was not boosting correctly. The waveform shown in Figure 5-7 was observed.

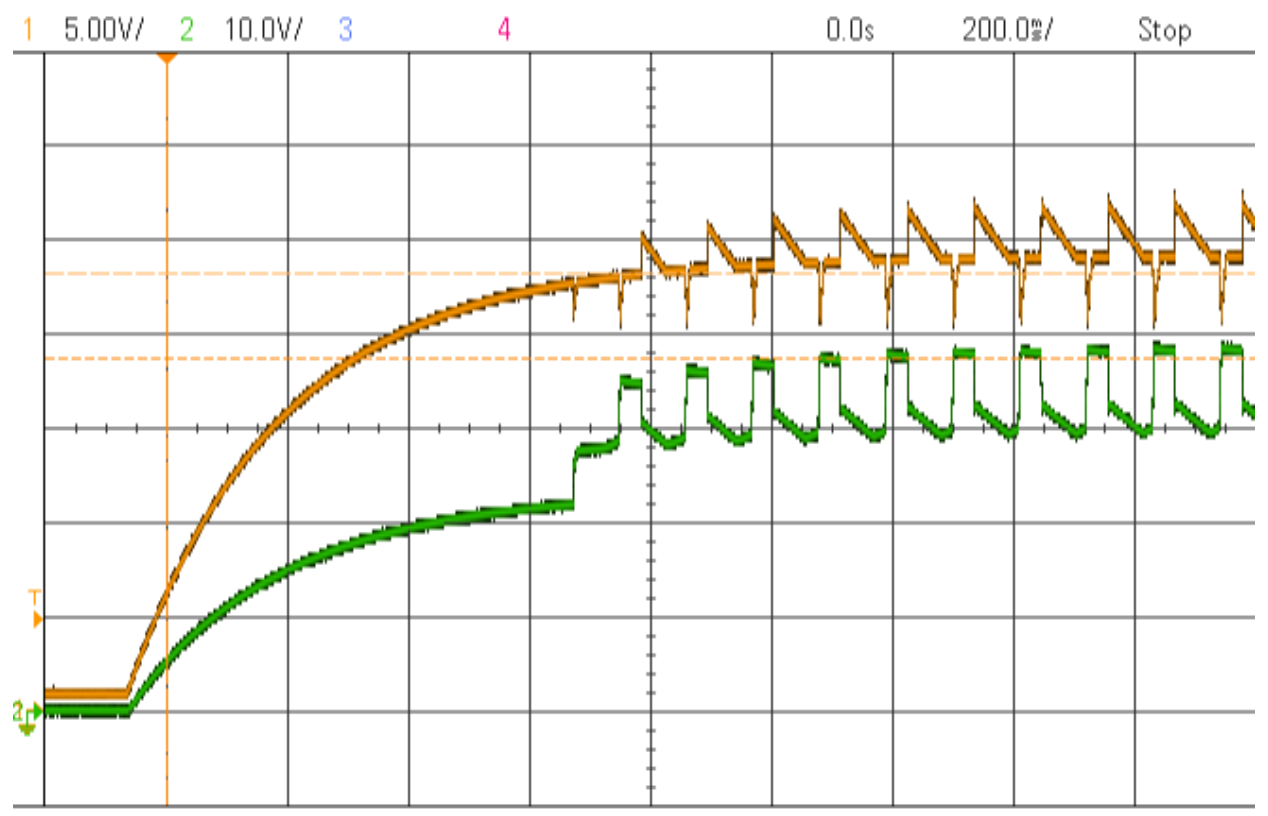

Figure 5-7: First Power on Observed Input (Ch. 1) and Output (Ch. 2)

Initially, the output voltage follows the input voltage by conducting through the body diodes of the MOSFETS and through the Or-ing diode. Then, at approximately $320 \mathrm{~ms}$, the input/output voltage reach the undervoltage lockout threshold and the converter goes through its turn-on sequence. As you can see on Channel 1 of Figure 5-7, the input voltage dips down. It dips down far enough to shut down the converter by reaching the undervoltage lockout threshold. Although there is hysteresis in that circuit to prevent such an event from occurring, the dip was excessive and caused this "hiccup" to occur and prevent the converter from properly regulating. The cause of this issue could be contributed to two reasons. The first reason is the fact that the input lines, including source connection and converter connections, created a significant impedance to the input to the 
converter circuitry. This created a significant voltage drop when the converter began boosting and drawing the increased current. A secondary cause to the drop was the fact that the input source had the current limit set too low which forces the source to reduce its output voltage to keep the current constant. The input current is high during startup since the output is not in regulation and needs to boost the output voltage to charge the bulk output capacitance. Once these two issues were resolved, the output came into regulation as shown in Figure 5-8.

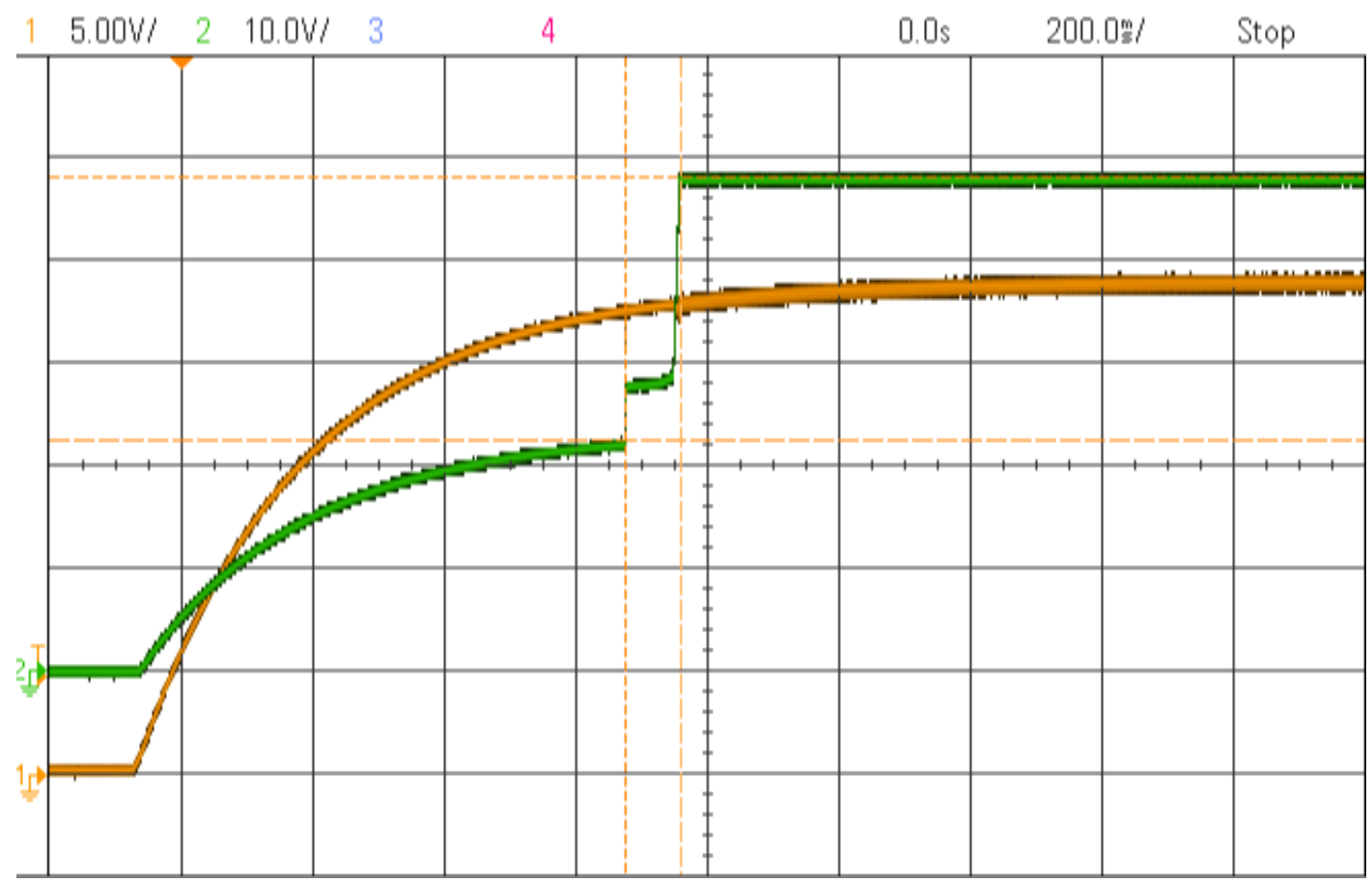

Figure 5-8: First Successful Turn on into Regulation. 


\subsection{Results}

\subsubsection{Single Power Supply Performance}

Initially, each power supply was tested individually to characterize the performance as a standalone converter. It was also useful to perform this testing on the first build in case changes were needed so they could be more easily incorporated into subsequent builds. This occurred as in the case of making the bias voltage modification as described in section 5.1.

When powering up the power supply with no load attached, the power supply tended to regulate at a higher voltage than nominal. The output point of regulation is prior to the Or-ing diode as described in section 4.1. When no load is attached, the Or-ing diode is conducting a minimal amount of current, if any. This means the voltage drop is minimal and the output capacitors are allowed to peak charge with only parasitics left to discharge the output. The output voltage regulation set-point must be set higher so that when the power supply is loaded to full load the voltage drop across the Or-ing diode is not high enough to cause the output to fall below the required regulation point. The power supply was characterized and at approximately $50 \mathrm{~mA}$ out, the output is within $0.1 \mathrm{~V}$ of the intended nominal output voltage. It is unlikely that there will be no load on the output when there is a device connected to the output so the higher regulation should not be an issue. Table 5-1 shows regulation characteristics of Power Supply 1 over the input line (22V-26V) and load range (0A-3.2A). The Power Supply is within the requirements specified in Section 3. 
Table 5-1 Power Supply Regulation

\begin{tabular}{|c|c|c|c|}
\cline { 3 - 4 } \multicolumn{1}{c|}{} & \multicolumn{2}{c|}{$\begin{array}{c}\text { Over Line and Load } \\
(>50 \mathrm{~mA})\end{array}$} \\
\cline { 2 - 4 } \multicolumn{1}{c|}{} & $\begin{array}{c}\text { No } \\
\text { Load }\end{array}$ & Max out & Min Out \\
\hline Voltage $(\mathrm{V})$ & 49.286 & 48.0 & 47.9 \\
\hline Percent & $2.7 \%$ & $0.0 \%$ & $0.2 \%$ \\
\hline Regulation & & & \\
\hline
\end{tabular}

When measuring output ripple, the oscilloscope should be bandwidth limited to $20 \mathrm{MHz}$ to avoid erroneous measurements. It is also assumed that there should be some sort of localized filtering at the point of measurement so that there is an accurate reading of the output ripple. A small amount of capacitance will filter out any external noise pickup and will provide a more accurate measurement for ripple. Using a tight scope probe, the output ripple of the unit was observed during various operating conditions. The worst-case ripple observed was during full load operation and is shown in Figure 5-9. This ripple for a standalone converter meets the requirement of Section 3, $286 \mathrm{mV}$ peak to peak measured compared to the $960 \mathrm{mV}$ peak to peak allowed. 


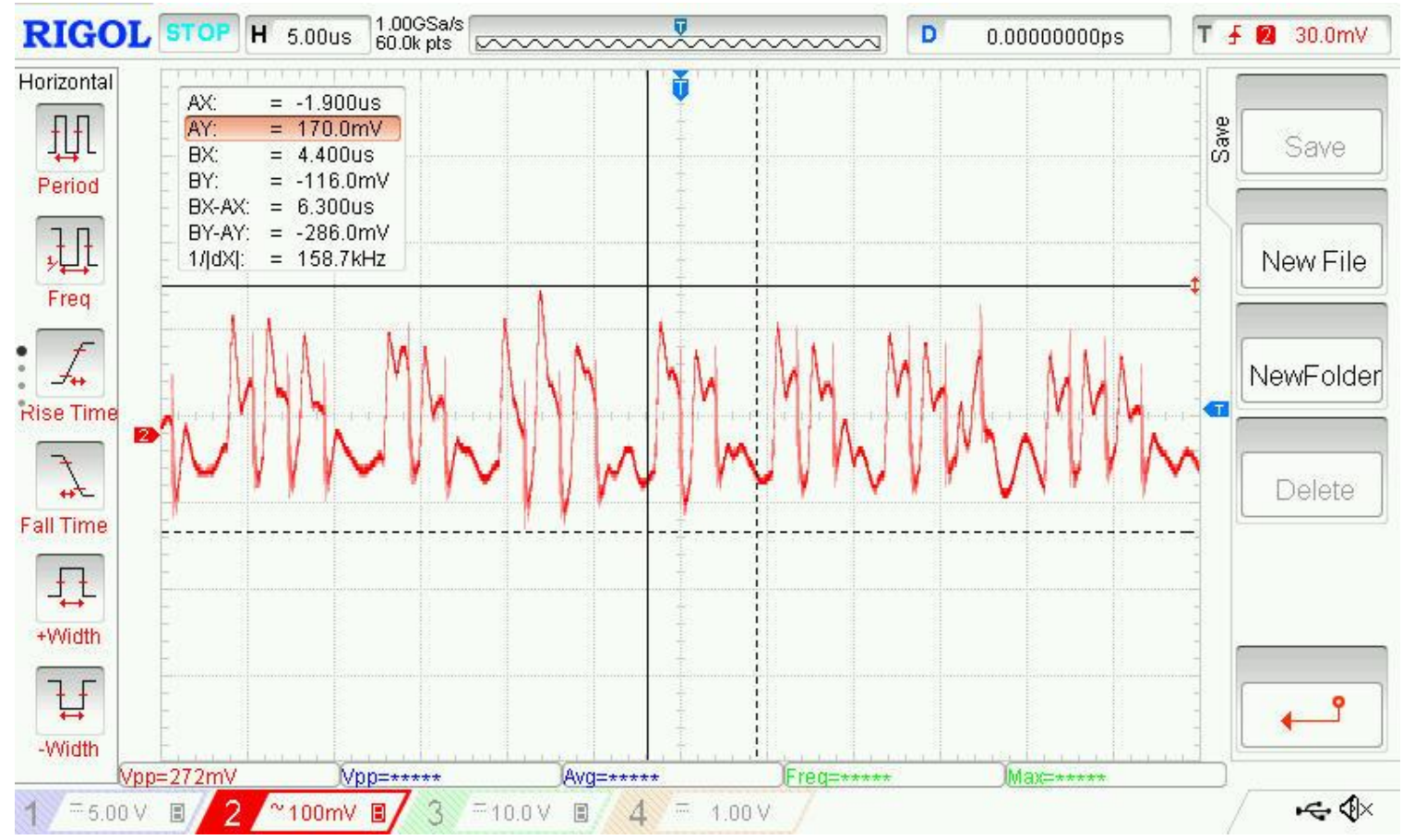

Figure 5-9: Power Supply 1 Ripple at Full Load

Data was also taken for the efficiency of the converter over the load and line range. The data for Power Supply 1 is shown in Figure 5-10.

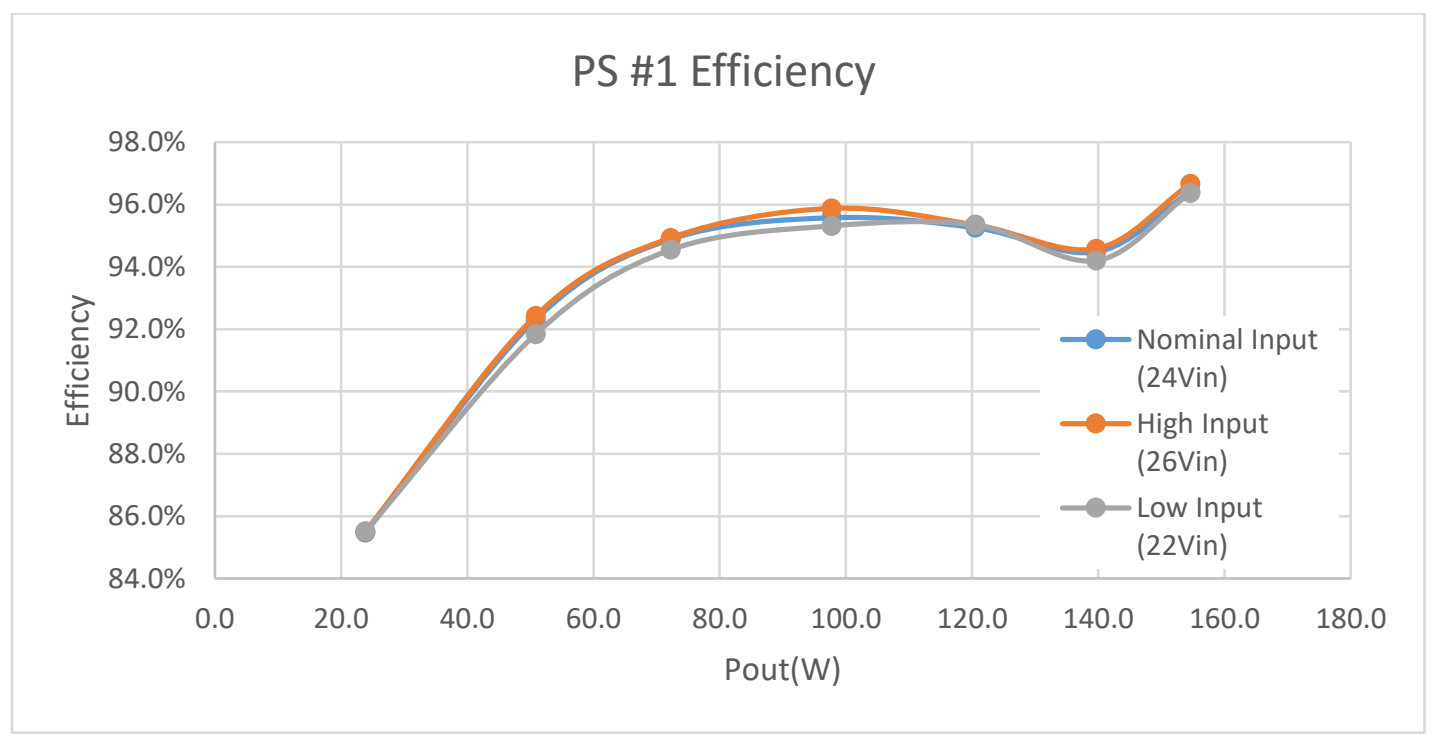

Figure 5-10: Power Supply 1 Efficiency 
Data was taken for each power supply and efficiency data for the remaining power supplies are shown in Figure 5-11, Figure 5-12, and Figure 5-13.

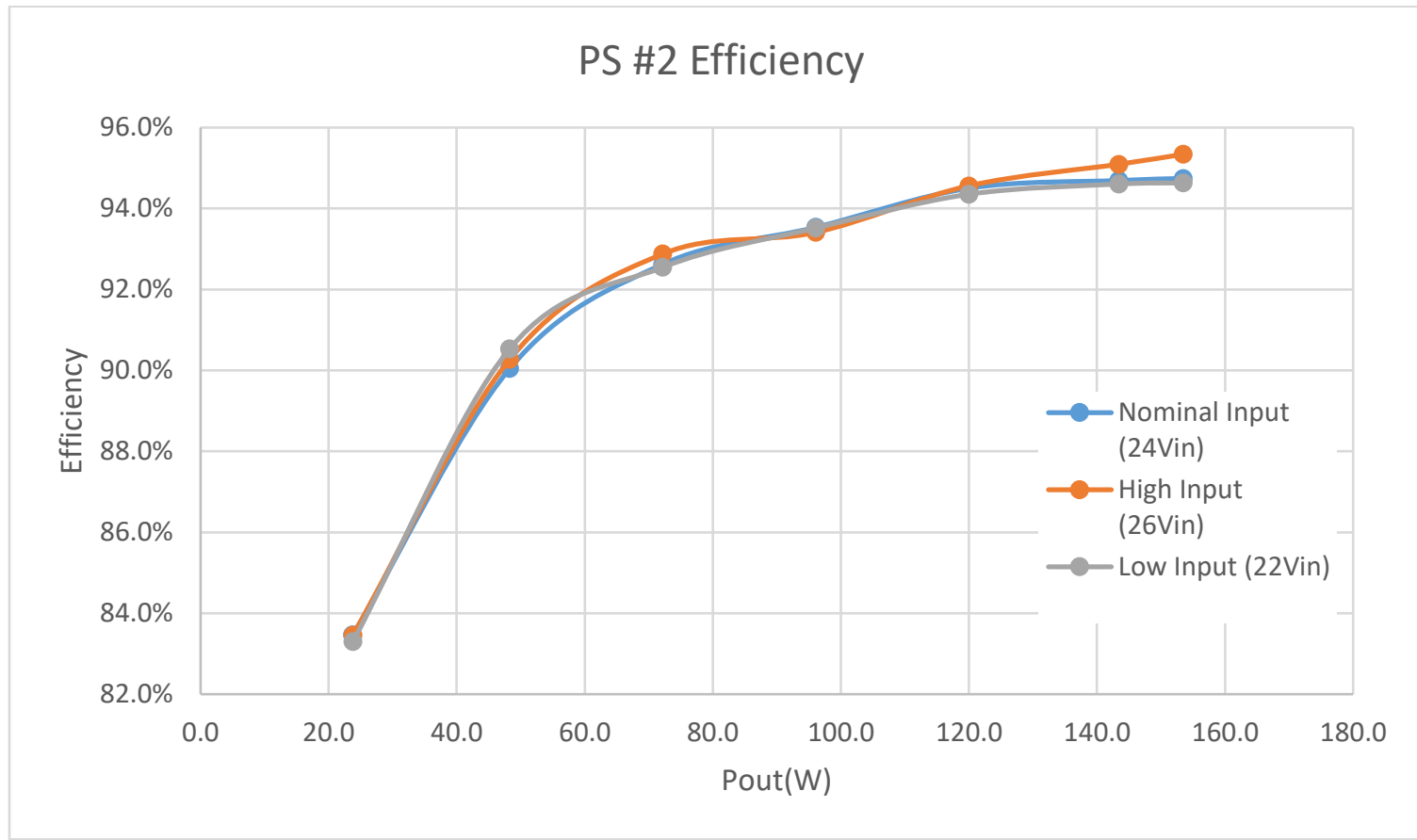

Figure 5-11: Power Supply 2 Efficiency

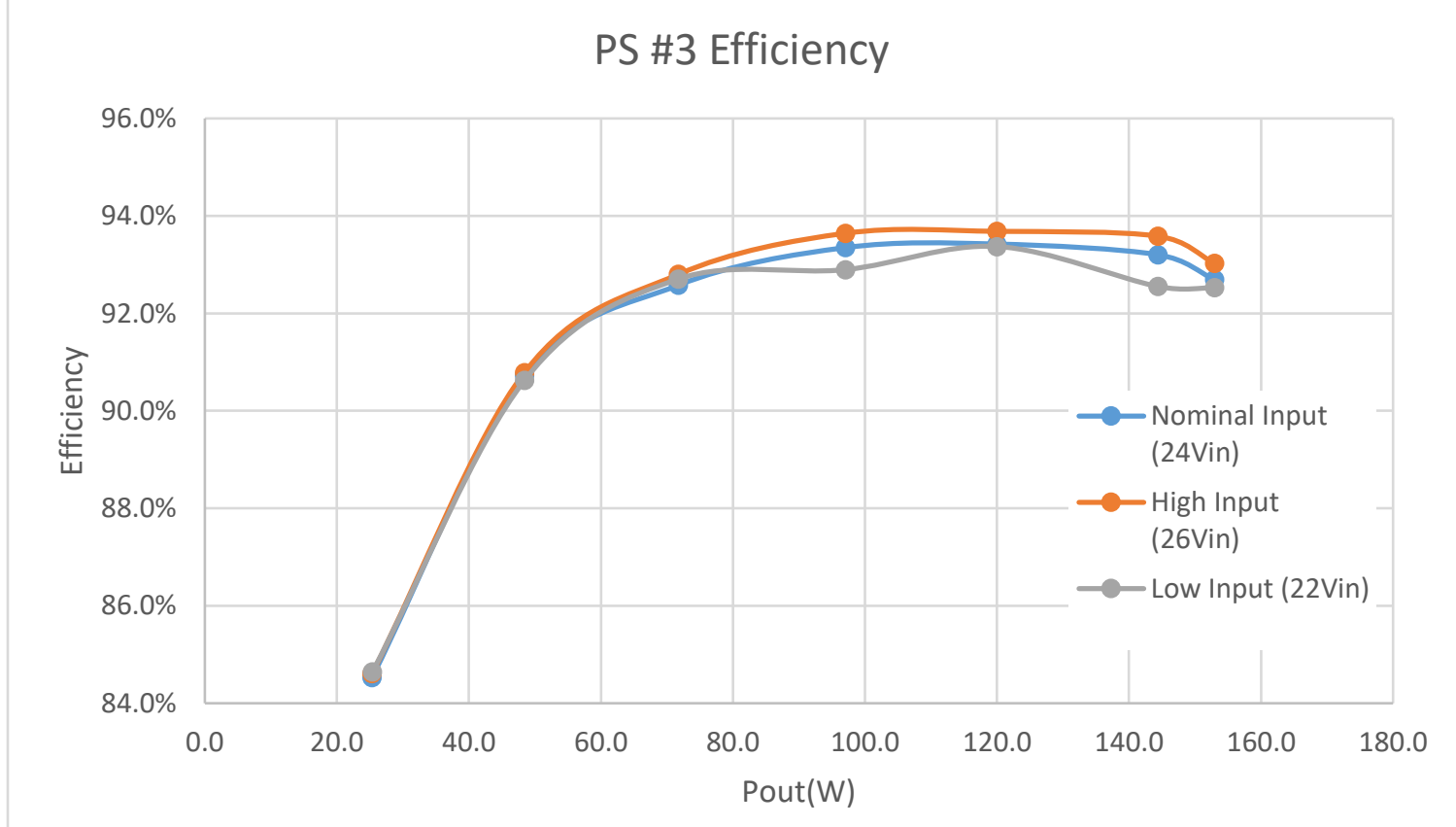

Figure 5-12: Power Supply 3 Efficiency 


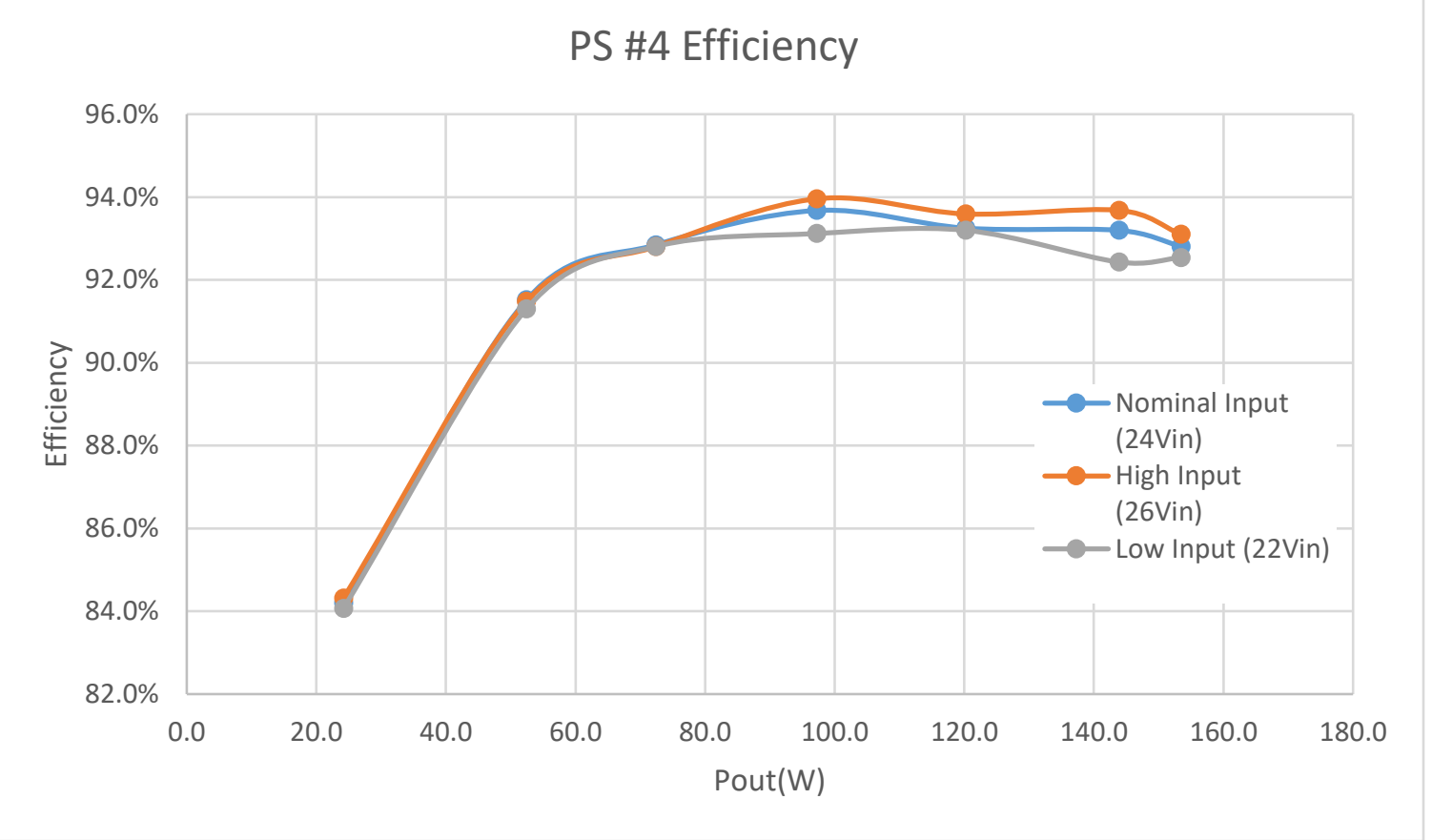

Figure 5-13: Power Supply 4 Efficiency

From the data shown in Figure 5-10 through Figure 5-13, the curves between each converter do not match up exactly. This is caused by various factors. There could be differences in the component characteristics such as on state resistance and forward voltage drop. The construction of the converter could have caused increased conduction losses if components do not have adequate soldering. Even the weather could play a role since component characteristics could change over temperature. Since there were extended gaps between test data being taken for each converter, the test setup and equipment also changed since equipment was being purchased throughout the process. A list of the equipment used is shown in Table 5-2. Although these various variables played a role in the outcome of the data, the fundamental characteristics were similar. 
Table 5-2: List of Test Equipment Used

\begin{tabular}{|c|c|c|c|}
\hline Description & Manufacturer & $\begin{array}{c}\text { Part } \\
\text { Number }\end{array}$ & Quantity \\
\hline Digital Multimeter & Tekpower & TP2844R & 1 \\
\hline Digital Multimeter & Tacklife & DM05 & 3 \\
\hline Digital Multimeter & Tacklife & DM02A & 4 \\
\hline Oscilloscope & Rigol & DS1054Z & 1 \\
\hline Electronic Load & Kunkin & KL283 & 2 \\
\hline $\begin{array}{c}\text { DC Power Supply } \\
(5 \mathrm{~A})\end{array}$ & Eventek & KPS305D & 1 \\
\hline $\begin{array}{c}\text { DC Power Supply } \\
(10 \mathrm{~A})\end{array}$ & Eventek & KPS3010D & 4 \\
\hline
\end{tabular}

\subsubsection{Parallel Power Supply Testing}

To reiterate what was previously stated, great care was taken in testing to prevent unsafe and potentially damaging conditions. Before testing the converters in parallel, voltage from a controlled source was back fed into the output of one of the power supplies to ensure the Or-ing diode circuit was working properly and no damage was observed on the unit under test. Once this was confirmed, parallel testing could continue, and the converters were characterized.

Initially, only two power supplies were built and then those two were tested in parallel to observe any interaction between the power supplies. This was done prior to building up the remaining power supplies to more easily incorporate any 
changes in the event of a change being needed to improve interoperability between the power supplies. The test showed there was nothing that caused any issues and the first two units operated successfully and the remaining power supplies could be constructed.

The power supply load sharing data for the first and second power supply is shown in Figure 5-14. Additional data was taken for the remaining power supplies to ensure each power supply was built correctly and validate there were no defects from the construction process. Each power supply was paralleled with another power supply and similar data was taken as in Figure 5-14. The power supplies tend to settle out and current share at approximately $7 \%$ load difference for loads of $150 \mathrm{~W}$ and above when two power supplies paralleled.

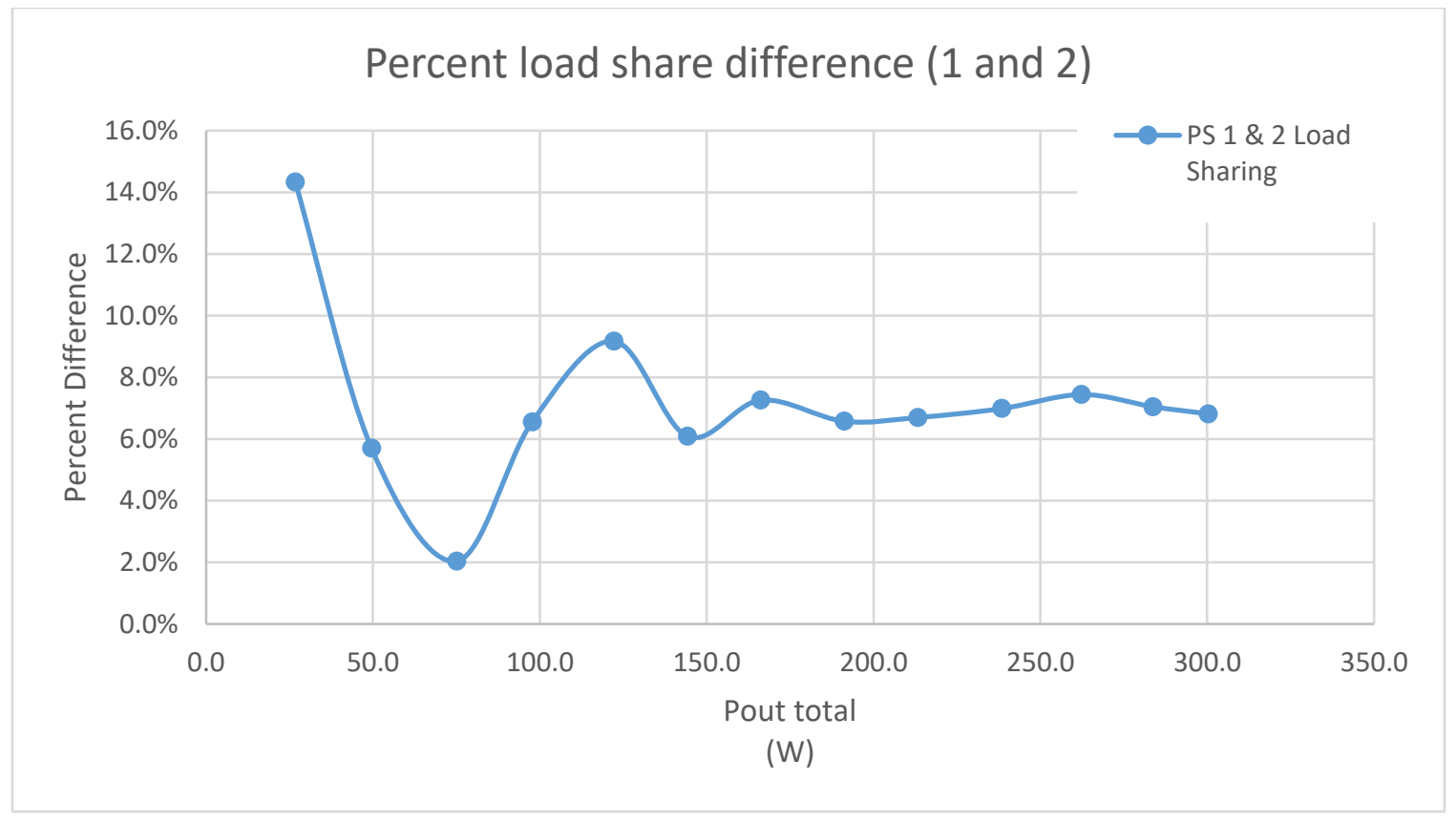

Figure 5-14: Power Supply 1 and 2 Load Share Difference

Each time power supplies were operated in parallel for the first time, the regulation point had to be dialed in for those units in operation. That initial dialing 
in of the regulation voltage is what provides the closest load sharing for that configuration. Below is data for the various units operating in parallel. As can be seen from Figure 5-15, Figure 5-16, and Figure 5-17, the load sharing between two power supplies does not stay constant over the load range. The two paralleled power supplies can alternate between providing more or less current. This is caused by differences in component characteristics and differences in line impedances.

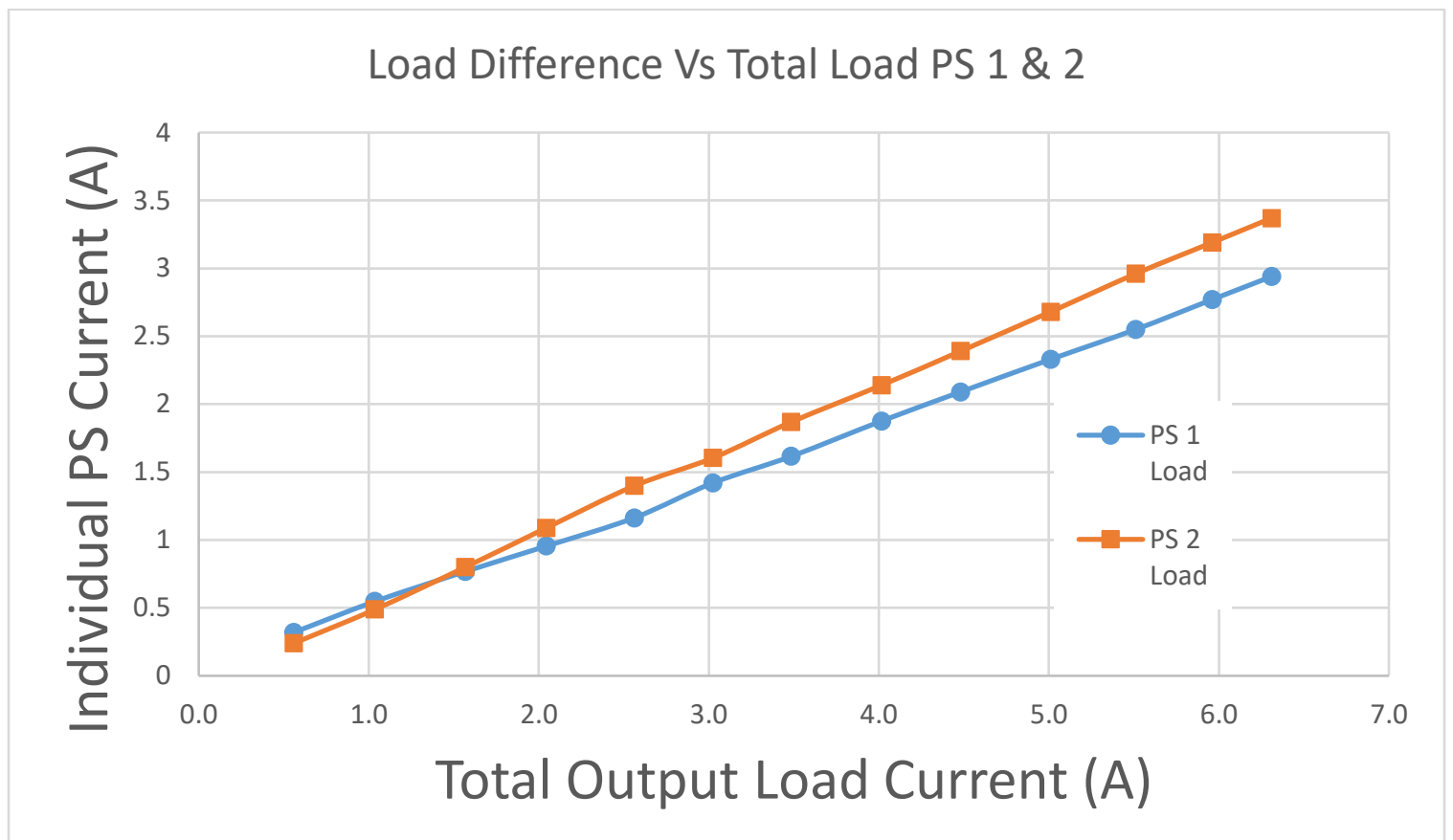

Figure 5-15: Load Difference PS 1 \& 2 


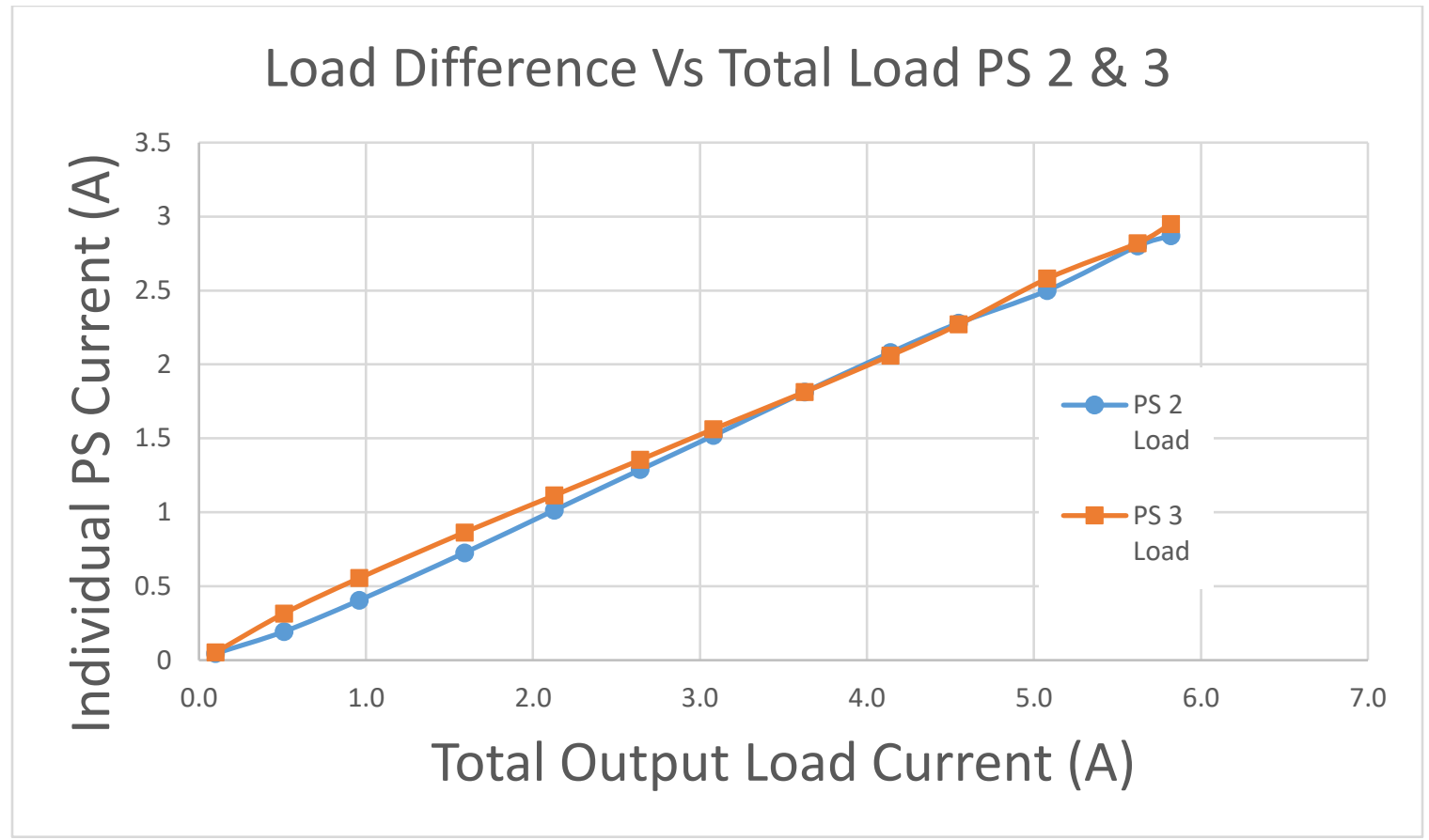

Figure 5-16: Load Difference PS 2 \& 3

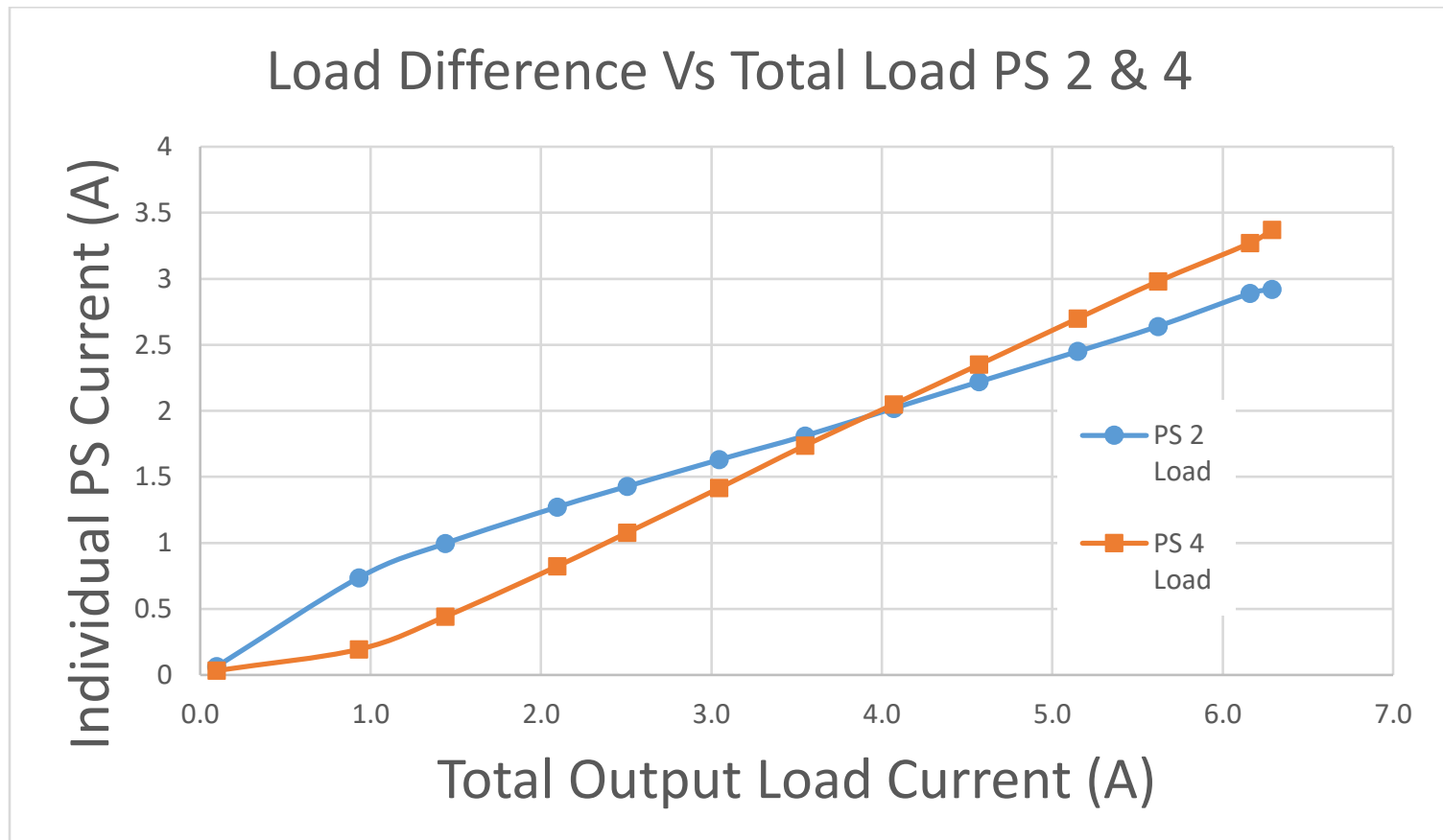

Figure 5-17: Load Difference PS 2 \& 4 
As indicated in previous sections, incremental steps were taken prior to operating the power supplies under the intended configuration to avoid mistakes and potential damage to the power supplies. The next step in the testing process was paralleling three power supplies and observing how they operate. Each converters output current was documented as well as the shared output voltage. The worst-case load sharing is shown in Figure 5-18. Initially the load sharing difference is large, but as the load is increased the converters share load more closely. Above approximately $270 \mathrm{~W}$ out, the converters are sharing within $10 \%$ of each other. The actual load curves while operating in parallel are shown in Figure 5-19.

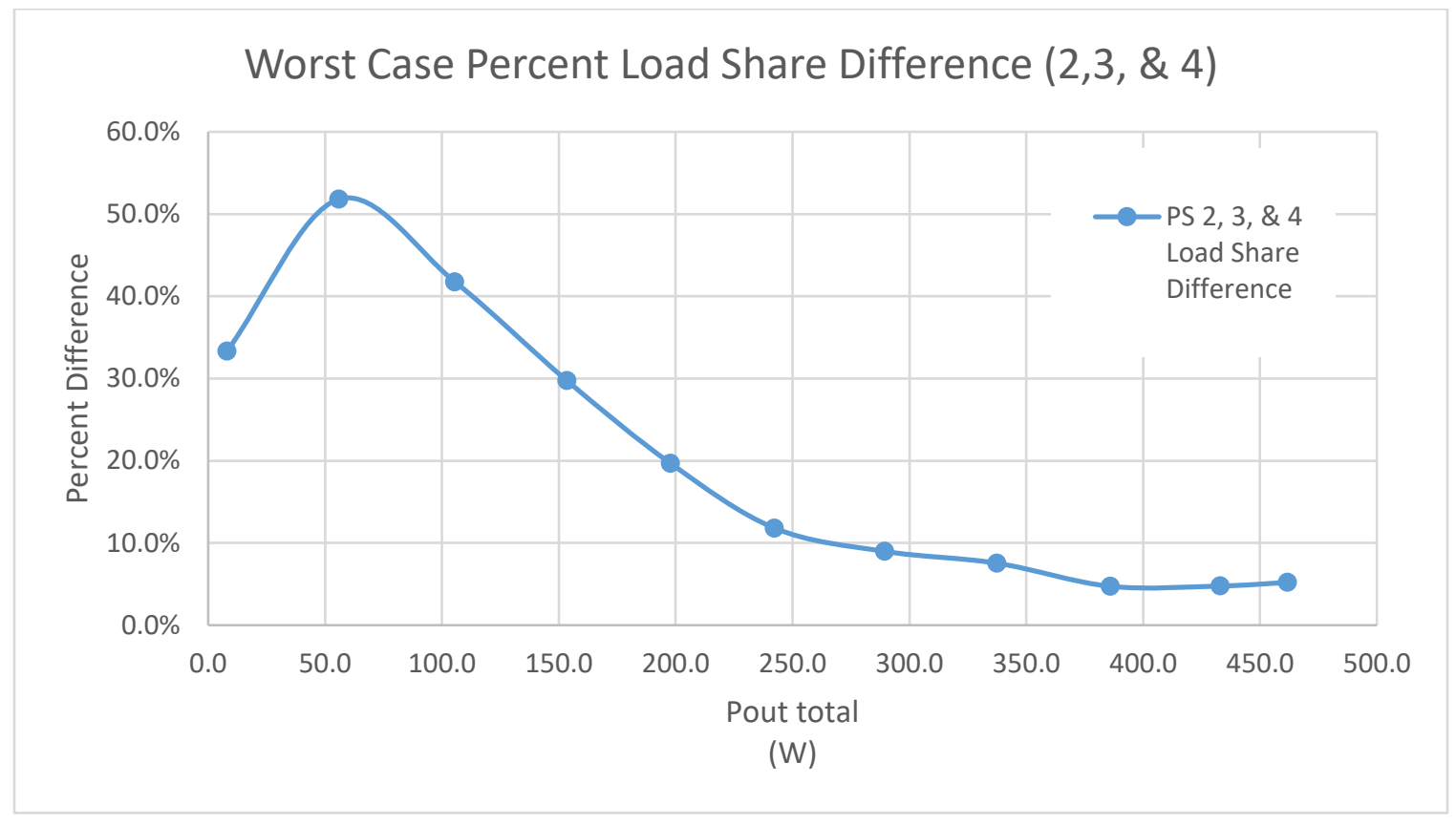

Figure 5-18: Worst Case Load Sharing for PS 2, 3, \& 4 


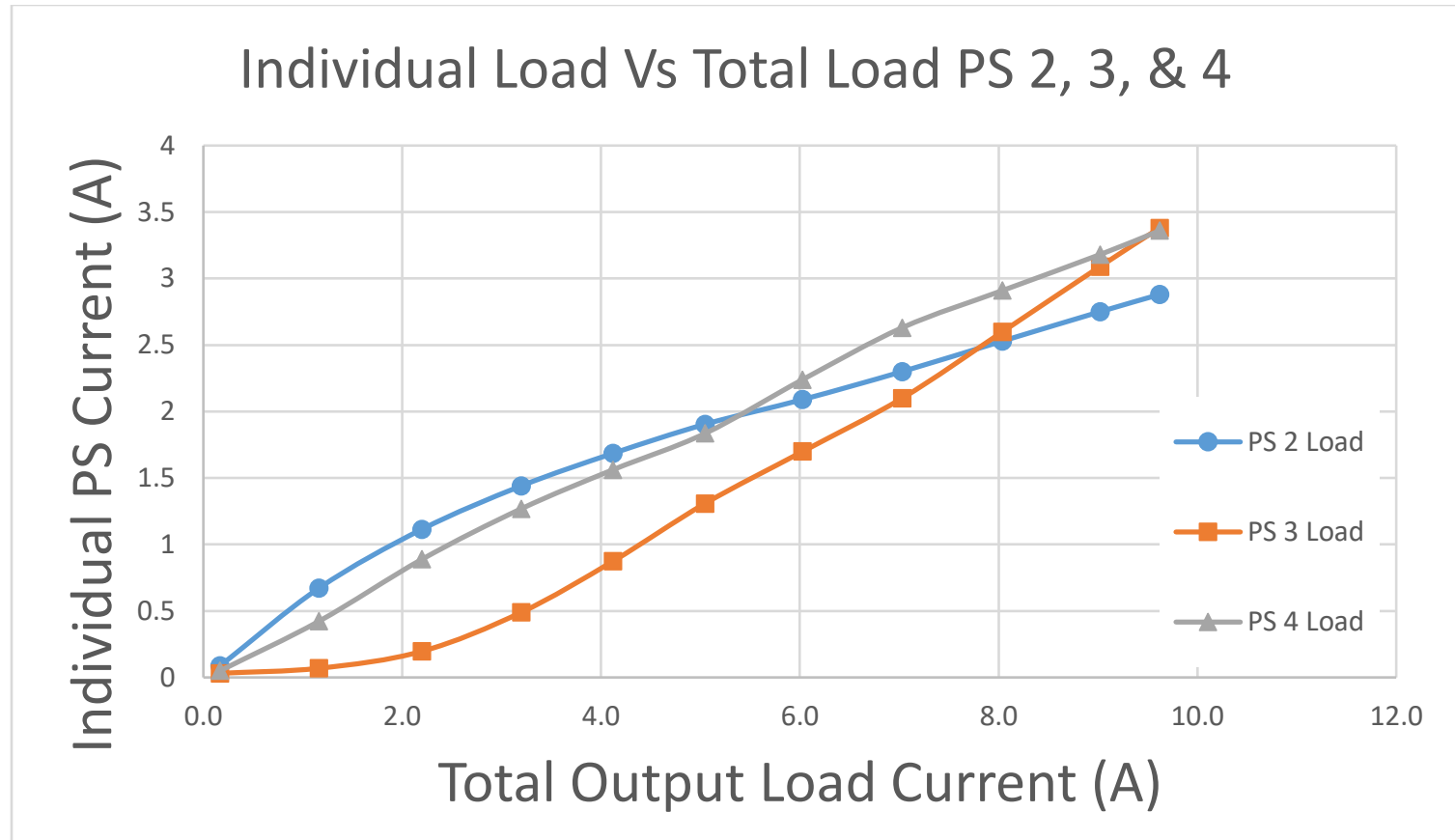

Figure 5-19: Load current of PS 2, 3, \& 4 operating in Parallel

The final configuration tested was operating the four converters while paralleling all outputs as shown in Figure 3-1. Testing parallel converters became increasingly more difficult to test due to lack of equipment and available test cabling. More Banana connectors were purchased to create custom wiring. Individual cables were easily constructed using 14-gauge, stranded wire and banana cables. To make paralleling outputs easier, a custom output wiring cable was created. The beginning of the wires had banana plugs and would connect to each of the outputs individually. Those four wires were stripped approximately $1.5 \mathrm{ft}$ from the end and then that section was combined with all the wires. This section provided a single point of connection between all the outputs. There was an additional $2.5 \mathrm{ft}$ for the cable to reach the electronic load. A picture of the output load cables is shown in Figure 5-20. 


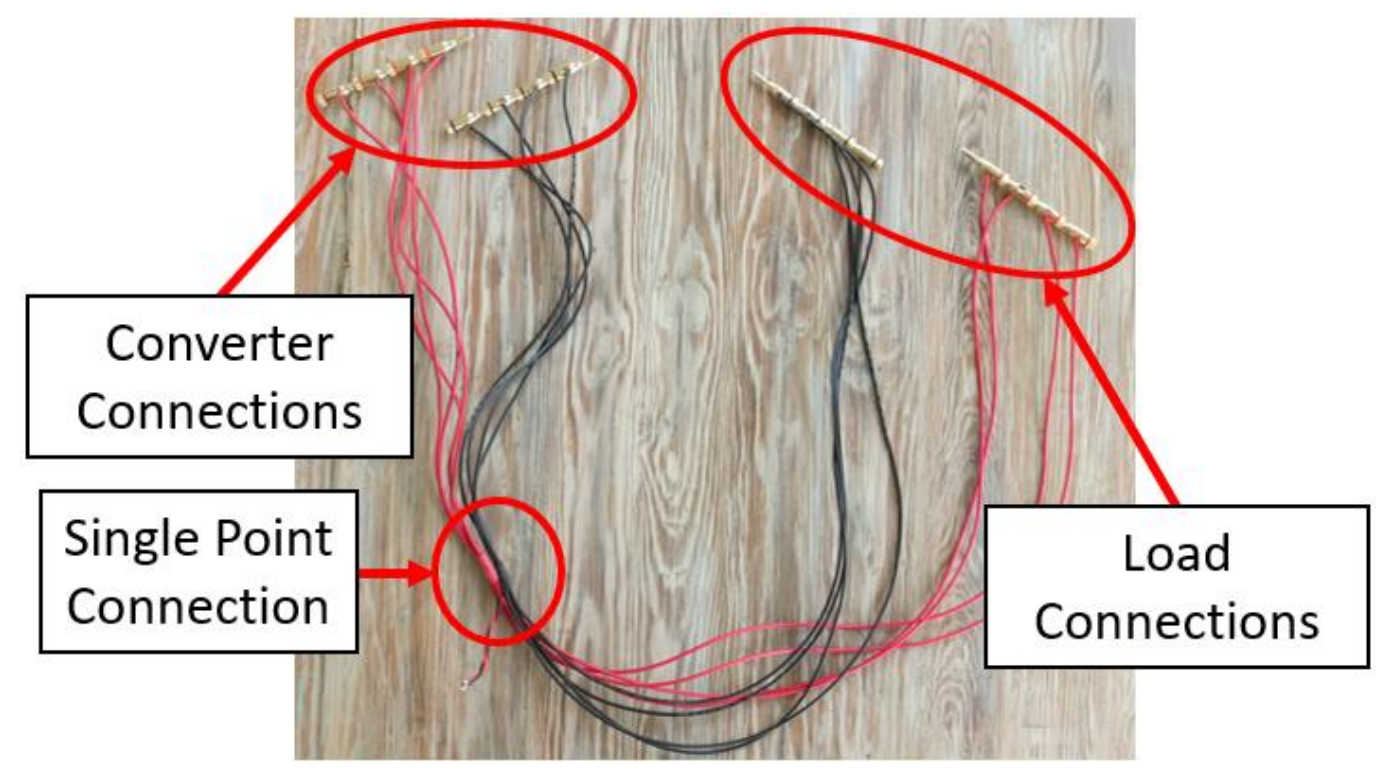

Figure 5-20: Custom Load Cables

Four individual sources were used to power four individual converters, the outputs of the converters were paralleled using a load cable. The load cable fed into two electronic loads, which each had two adjustable loads. The output currents of each of the converters were monitored using multimeters. The combined output voltage, at the single point connection, was monitored using a multimeter. Some of the input voltages and output voltages (at the converter) were also monitored with leftover equipment. A block diagram of the setup is shown in Figure 5-21 and the actual setup is shown in Figure 5-22. 


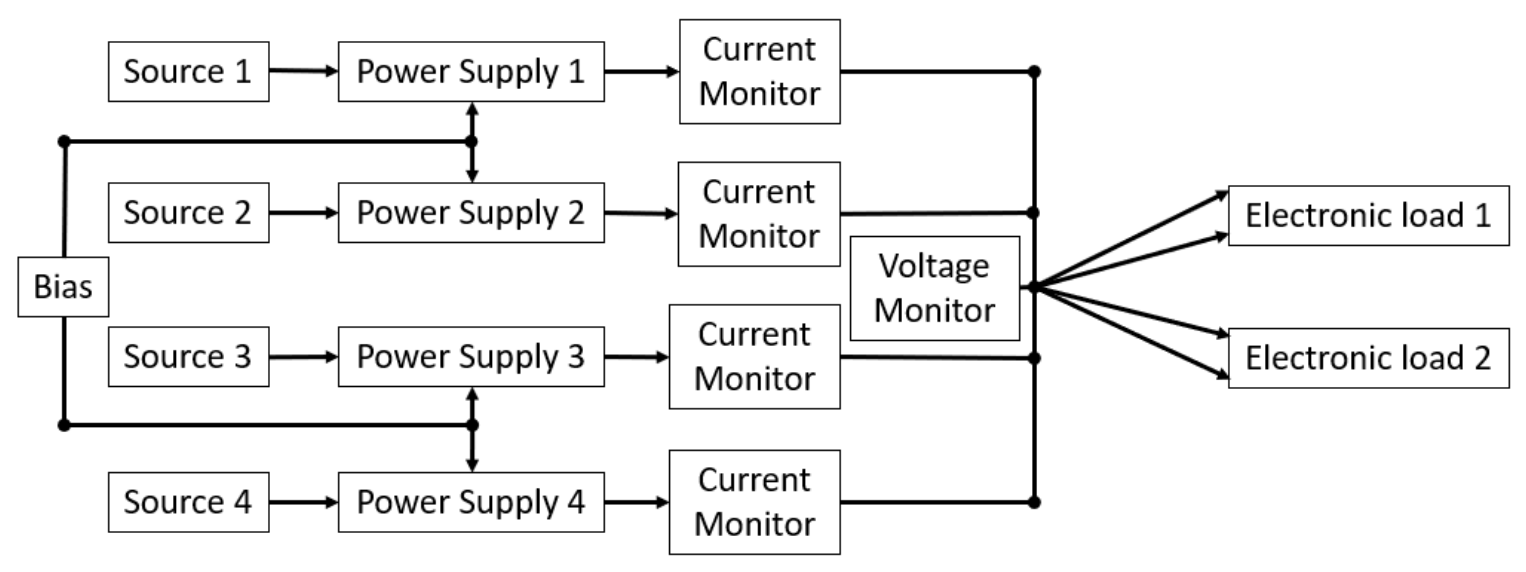

Figure 5-21: Block Diagram of Four Paralleled Converters

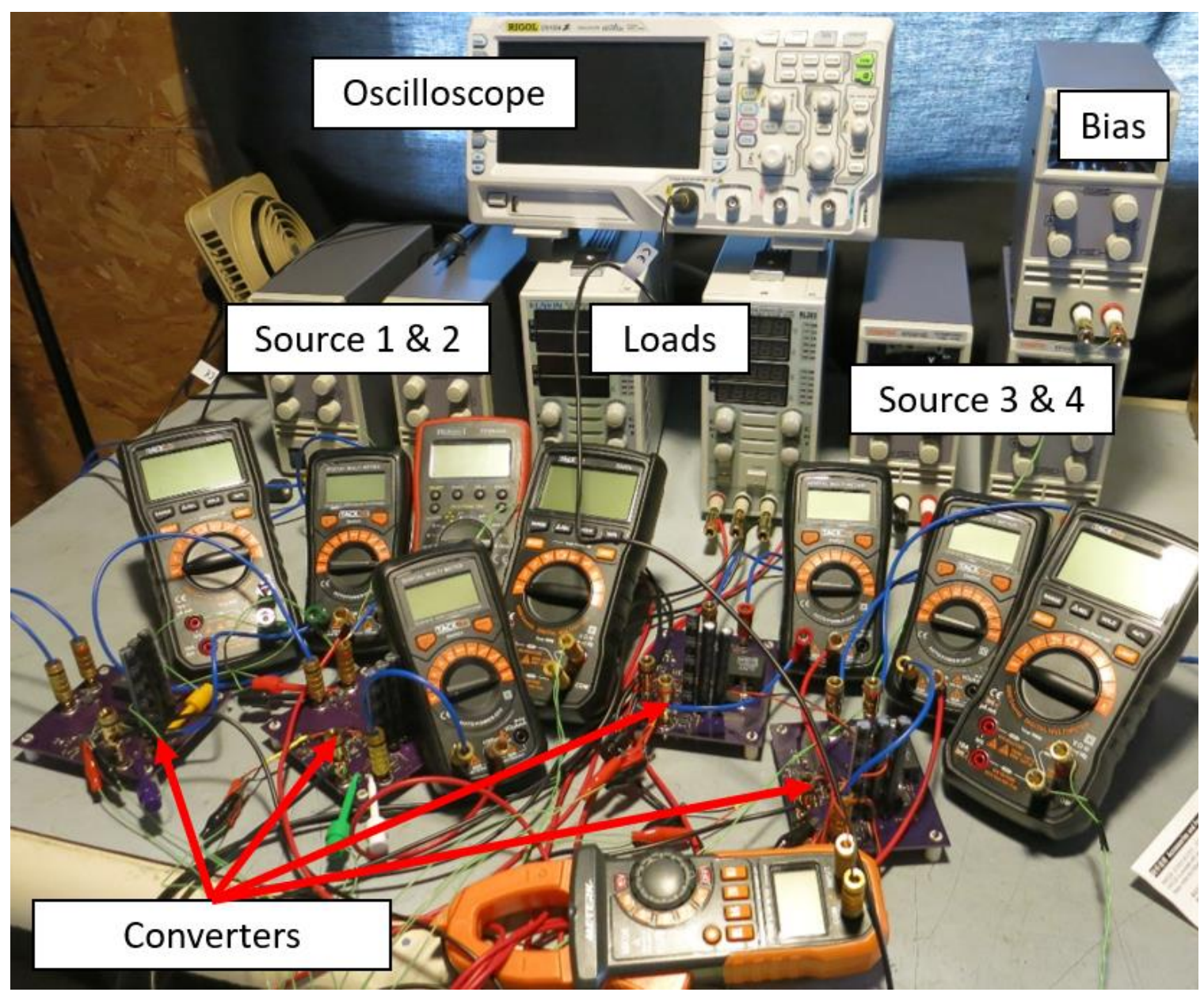

Figure 5-22: Four Converters Paralleled Testing Setup 
Data was taken of each output converter current using the multimeter to monitor the currents. The converters outputs were paralleled, and data was collected for the individual currents as well as the combined output voltage. Figure 5-23 shows the individual load currents supplied by each of the converters over the total load range. The data collected was also used to capture the worst-case load difference over the entire power range and is shown in Figure 5-24. The output current difference is less than $10 \%$ worst-case, above loads of approximately $320 \mathrm{~W}$ out. In total, the four combined converters were able to supply a $48 \mathrm{~V}$ load with a measured $12.9 \mathrm{~A}$ equating to approximately $620 \mathrm{~W}$ which meets the requirements outlined in Section 3. The efficiency of the combined converters was not taken but efficiency of the converters should be approximately the same as the individual converters. From Figure 5-10 through Figure 5-13, all converters have efficiency above $92 \%$. It is safe to assume that the combined efficiency of the 4 operating in parallel meets the requirement of $75 \%$ efficiency and will be an average of the individual converter efficiencies. 


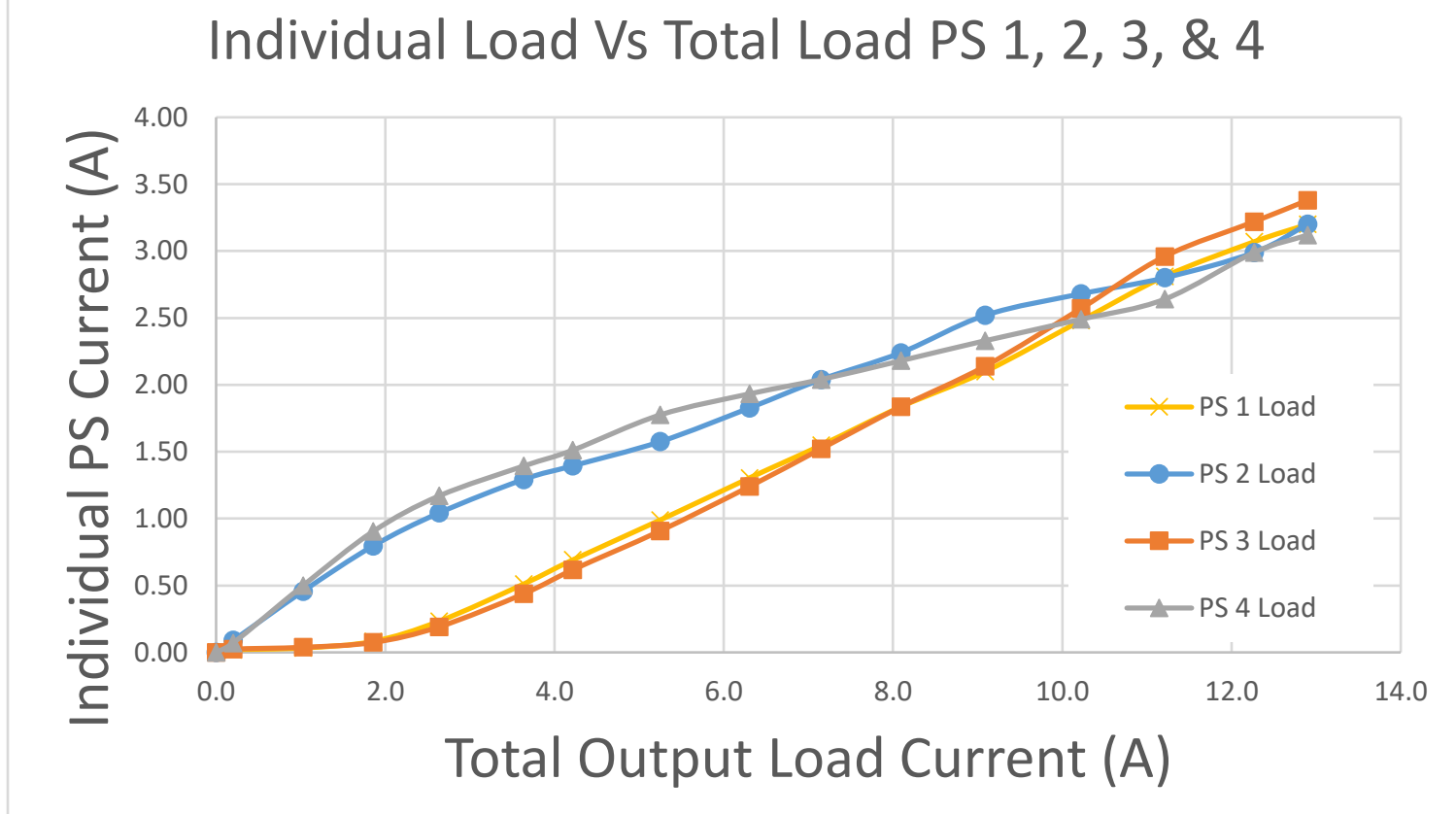

Figure 5-23: Four Paralleled Converters Shared Load Current

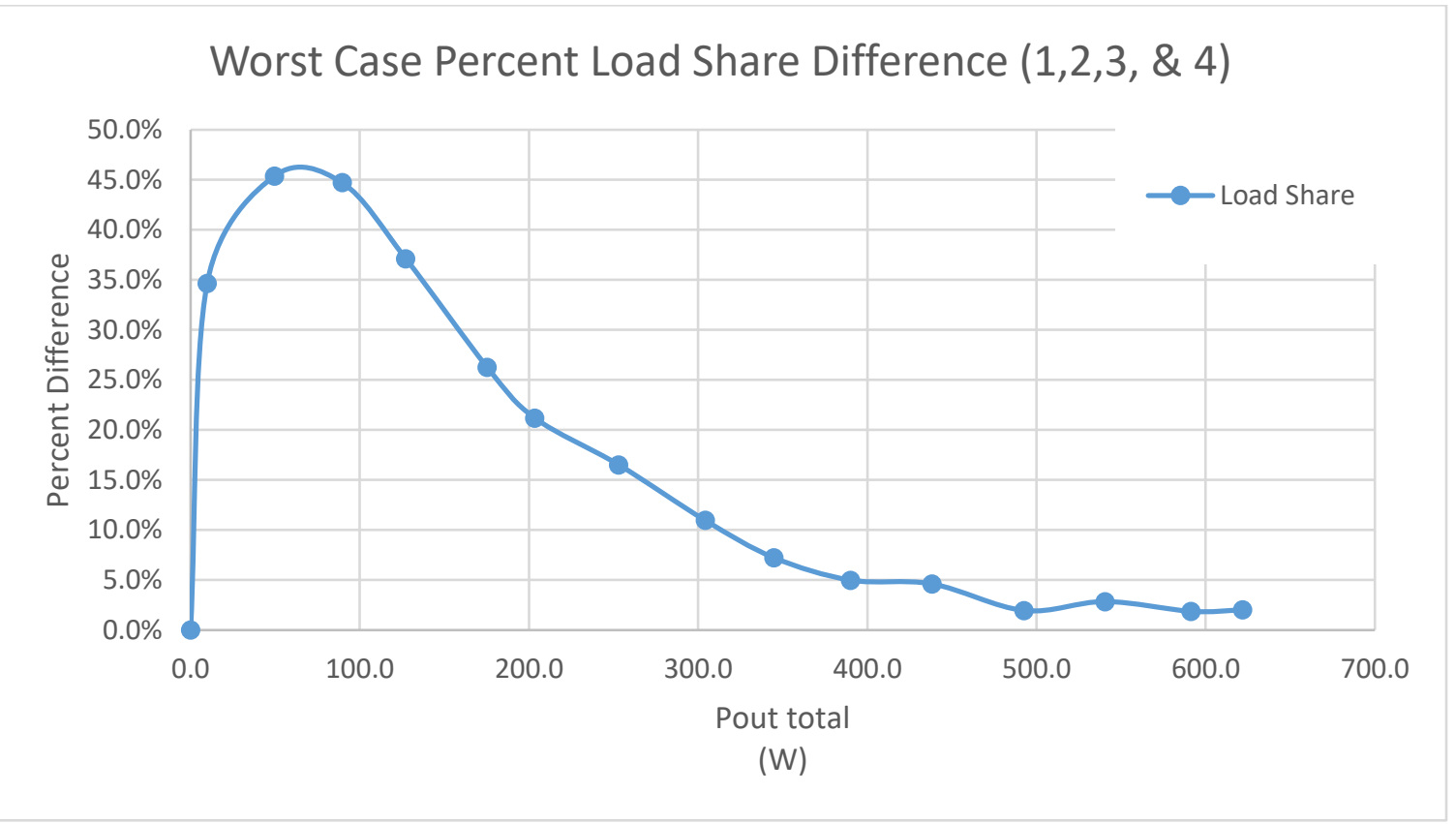

Figure 5-24: Worst Case Load Difference of 4 Paralleled Converters. 
In addition to the current sharing data taken, ripple data was also taken. Ripple data was taken in the paralleled configuration since the output ripple of each of the converters could interact with each other. The ripple was taken at the common point and a small amount of capacitance was added since the measurement point had a large loop area susceptible to high frequency noise. With $1 \mu \mathrm{F}$ of local capacitance, the worst-case ripple was measured to be $360 \mathrm{mV}$ peak to peak and is shown in Figure 5-25. The ripple is larger than was seen on a single converter since the individual converters are most likely operating at slightly different frequencies and the ripple waveforms will create constructive interference. So, Figure 5-25 demonstrates constructive interference when the ripple is larger and destructive interference when the ripple is reduced. Even with this interference, the ripple remained within the requirements of $2 \%, 960 \mathrm{mVpp}$.

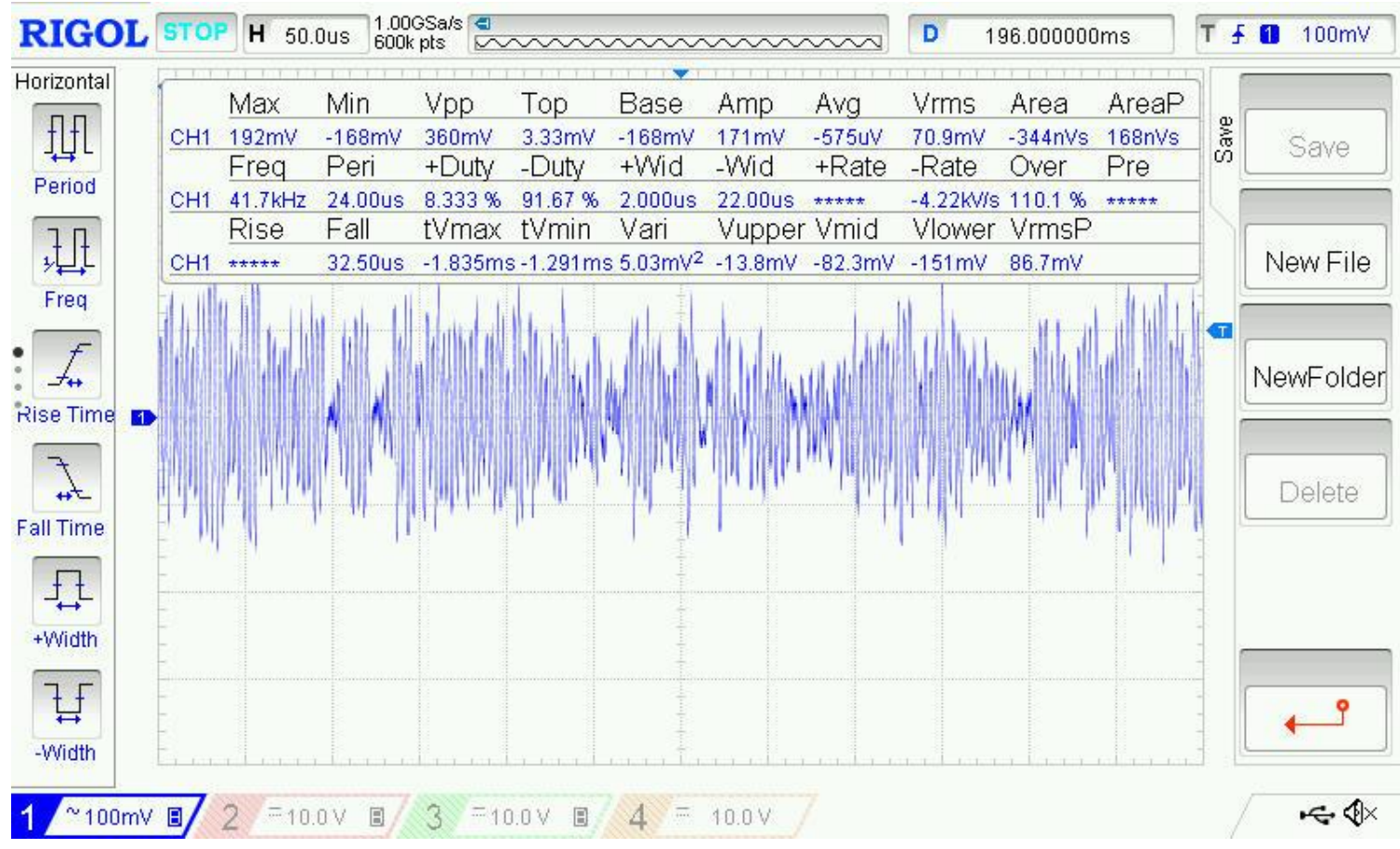

Figure 5-25 Ripple at 12.8A Total Load Current 


\section{Conclusion}

Great care was taken in the development of this converter to make it a feasible design. Overall this project was successful in developing and demonstrating the possibility of using multiple input sources to provide a higher power single output through the use of parallelable converters. The fundamental requirements set out for this design were all met and included the use of 4 individual $24 \mathrm{~V}$ nominal input sources, a $48 \mathrm{~V}$ output providing $600 \mathrm{~W}$ total output power, greater than $75 \%$ efficiency, tight output regulation, and low output ripple. The costs of the converters were kept relatively low by using readily available commercial components. There were some issues seen during the development which were rectified to ensure success of the design.

The issue which was seen regarding the low bias voltage in Section 5.1 should be incorporated into the design. This would imply incorporating the modifications of the external bias configuration. In addition, it would be ideal to have a local bias converter which is powered by the same input as the main converter. Incorporating this bias would allow the converter to be a standalone package. Since the efficiency of the converter is relatively high, it may be possible to incorporate a simple linear regulator if the bias power is low and the additional losses are tolerable. Additional thermal considerations would have to be made to ensure proper cooling is provided for the linear regulator.

Although in practice this design works, there is room for improvement. Since this project would be used in conditions where there would be extended use of the product, it is important to make sure the design is robust. The improvements which 
should be incorporated would be protection circuitry. Protection circuitry would be needed to protect the converter from any abnormal conditions which could potentially cause failures. A more robust design would reduce the likelihood of failures, reduce overall costs, and increase the life of the product. In addition, there are other improvements which could be made to allow the converter to be used for additional scenarios. Here I would like to discuss some potential improvements to the design.

The first improvement which should be made would be to have the ability to operate the converter over a wider input voltage range. This could allow the use of different input sources which operate over this larger range. When there are more options to use, there is a larger group of individuals this product could serve. Essentially it would increase the number of sources it would be compatible with which would then expand the consumer base. This could be achieved by increasing the current rating of the power components which would improve the low voltage operational range. In addition, higher output power at nominal input voltages could potentially be achieved with the increased current capabilities. In order to operate at higher input voltages, components with higher voltage ratings could be used. These improvements should only be incorporated if there is a need and if the higher costs of better performing components is not significant.

In order to prevent the input source from damaging the converter when the input limits are exceeded, there should be an over voltage protection circuit. The circuit would shut down the converter if the input voltage is too high for the ratings of the components. This could easily be incorporated by using the same circuit that 
was used for the undervoltage protection circuit as discussed in Section 4.1. This circuit consisted of a comparator circuit with hysteresis which toggled the Run/Soft Start pin of the controller whenever the sensed threshold was exceeded.

There is also the potential for the output load to draw excess current which could damage the converter and also the source. Although the controller chip had the ability to incorporate overcurrent protection of the low side switch it was not feasible to use in this design. The low side on-state resistance of the MOSFET were kept low to reduce the power losses of the converter as much as possible. This on-state resistance is also used by the controller chip to monitor the current by sensing the voltage drop across the MOSFET. The overcurrent threshold is inversely proportional to the on-state resistance so to use this functionality, another MOSFET with higher on-state resistance would have to be used. This would have an adverse effect to the power dissipation and efficiency so an external sense resistor could be used to measure the output current of the converter. This sense current could then provide feedback to shutdown the converter and restart after some thermally insignificant rate in the event that the overcurrent condition is cleared. It would also be nice to have some sort of indicator light which would notify the user that an overcurrent condition was observed which could help in troubleshooting the issue.

Overall this project met the intent of supporting the required performance for the DC House project. The design shows the potential for further growth to expand on the performance capabilities of the project. This includes the ability to use more than four input sources to supply greater total output power capabilities. 


\section{BIBLIOGRAPHY}

[1] D. A. Jones, "Electrical engineering: the backbone of society," in IEE Proceedings A - Science, Measurement and Technology, vol. 138, no. 1, pp. 1-10, Jan. 1991.

URL: http://ieeexplore.ieee.org.ezproxy.lib.calpoly.edu/stamp/stamp.jsp?tp $=\&$ arnumber $=61630$ \&isnumber $=2242$

[2] Bose, Bimal K., "Power electronics" Engineering and Technology History Wiki, University of Tennessee (Knoxville), 15 September 2014, [Online] Available: https://ethw.org/Power_electronics\#Power_Converters

[3] Sulzberger, Carl., "Milestones:Pearl Street Station, 1882", Engineering and Technology History Wiki, IEEE Region 1, 10 October 2011, [Online], Available: https://ethw.org/Milestones:Pearl_Street_Station,_1882

[4] Rashid, Muhammad H., "Power Electronics Circuits, Devices, and Applications Third Edition", Pearson, 2003

[5] Dilip Ahuja and Marika Tatsutani, "Sustainable energy for developing countries", S.A.P.I.EN.S 2.1, 27 November 2009, [Online], URL : http://journals.openedition.org/sapiens/823

[6] Taufik, "The DC House Project: An Alternate Solution for Rural Electrification", IEEE Global Humanitarian Technology Conference, October 2014.

[7] Wong, Taffy Chi Kin. "Multiple Input Single Output DC-DC Converter for the DC House Project". October 2011.

[8] Jong, Owen. "Multiple Input Single Output (MISO) DC-DC Converter For the DC House Project". 2012

[9] B. T. Irving and M. M. Jovanovic, "Analysis, design, and performance evaluation of droop current-sharing method," APEC 2000. Fifteenth Annual IEEE Applied Power Electronics Conference and Exposition (Cat. No.00CH37058), New Orleans, LA, USA, 2000, pp. 235-241 vol.1.doi: 10.1109/APEC.2000.826110

URL:

http://ieeexplore.ieee.org/stamp/stamp.jsp?tp=\&arnumber=826110\&isnum ber $=17861$

[10] Linear Technology, "60V Current Mode Synchronous Step-Up Controller," LTC3814-5 datasheet, Jan 2011 


\section{APPENDIX A}
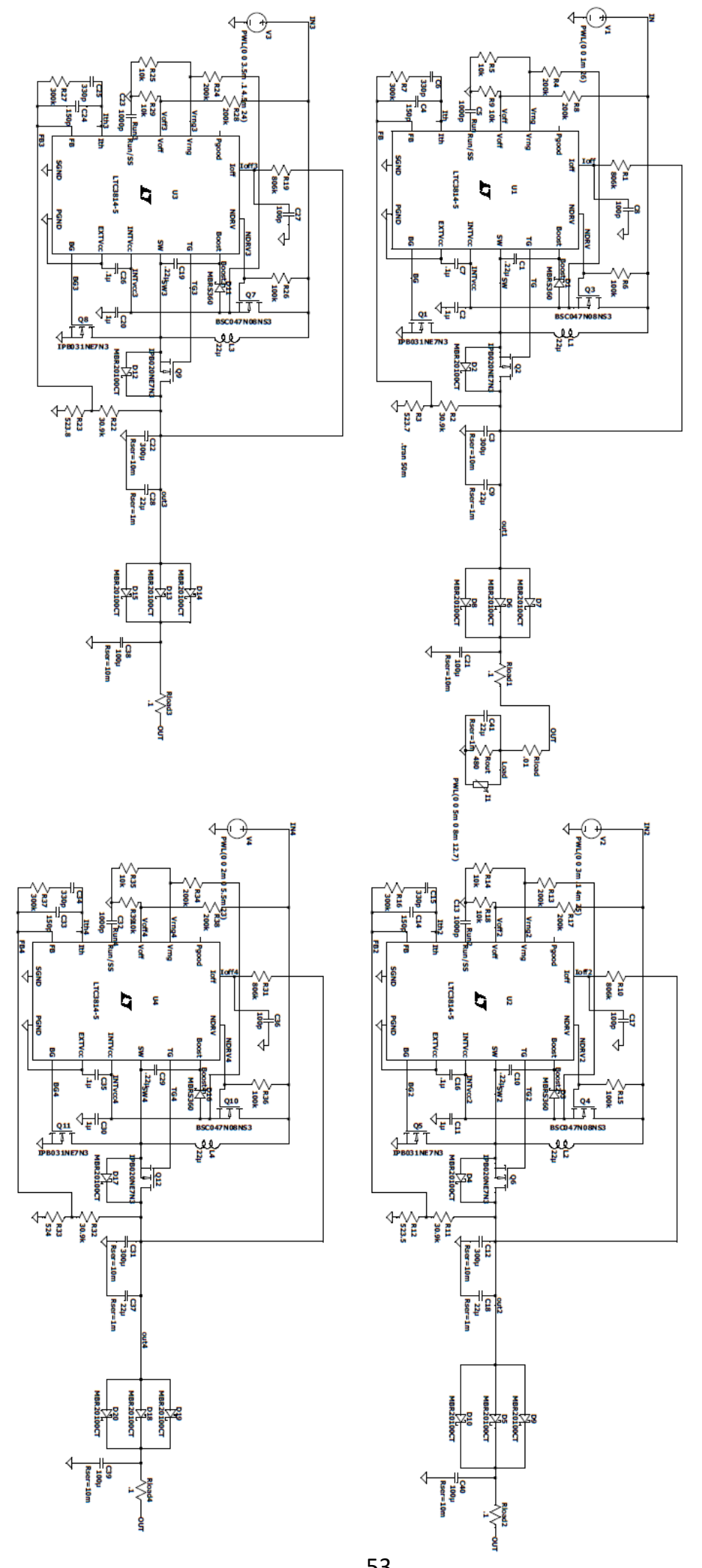


\section{APPENDIX B}

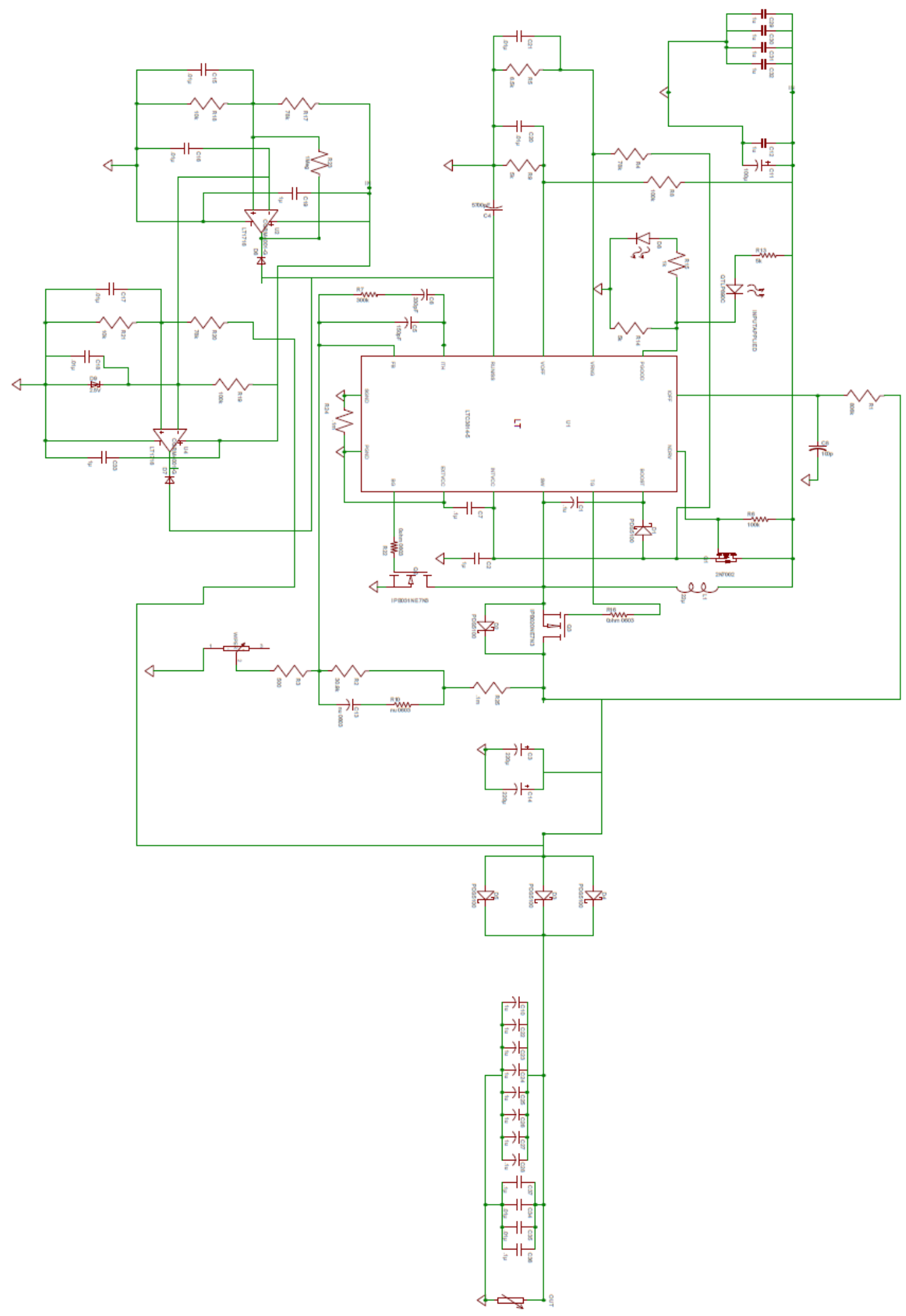




\section{APPENDIX C}

\begin{tabular}{|c|c|c|c|c|c|c|}
\hline Part & Mfg PN & $\begin{array}{l}\text { Qty Per } \\
\text { Board } \\
\end{array}$ & & Unit & Cos & Board \\
\hline STAND1 & 8841 & \multirow{4}{*}{4} & \multirow{4}{*}{$\$$} & \multirow{4}{*}{0.27} & \multirow{4}{*}{$\$$} & \multirow{4}{*}{1.07} \\
\hline STAND2 & 8841 & & & & & \\
\hline STAND3 & 8841 & & & & & \\
\hline STAND4 & 8841 & & & & & \\
\hline L1 & 74435582200 & 1 & $\$$ & 7.83 & $\$$ & 7.83 \\
\hline C3 & 100TXW220MEFC8X60 & \multirow{3}{*}{3} & \multirow{3}{*}{$\$$} & \multirow{3}{*}{1.51} & \multirow{3}{*}{$\$$} & \multirow{3}{*}{4.53} \\
\hline C9 & 100TXW220MEFC8X60 & & & & & \\
\hline C14 & 100TXW220MEFC8X60 & & & & & \\
\hline V IN & $150080 S S 75000$ & 1 & $\$$ & 0.29 & $\$$ & 0.29 \\
\hline IN_GOOD & 150080 VS75000 & 1 & $\$$ & 0.29 & $\$$ & 0.29 \\
\hline R23 & $2-1614885-8$ & 1 & & 0.18 & $\$$ & 0.18 \\
\hline Q1 & 2N7002P, 215 & 1 & $\$$ & 0.13 & $\$$ & 0.13 \\
\hline R2 & $4-2176093-9$ & 1 & $\$$ & 0.54 & $\$$ & 0.54 \\
\hline PAD1 & $575-4$ & \multirow{4}{*}{4} & \multirow{4}{*}{$\$$} & \multirow{4}{*}{0.75} & \multirow{4}{*}{$\$$} & \multirow{4}{*}{2.98} \\
\hline PAD2 & $575-4$ & & & & & \\
\hline PAD3 & $575-4$ & & & & & \\
\hline PAD4 & $575-4$ & & & & & \\
\hline D6 & BAT46ZFILM & \multirow{2}{*}{2} & \multirow{2}{*}{$\$$} & \multirow{2}{*}{0.28} & \multirow{2}{*}{$\$$} & \multirow{2}{*}{0.55} \\
\hline D7 & BAT46ZFILM & & & & & \\
\hline C4 & C0603C563J4RACTU & 1 & $\$$ & 0.31 & $\$$ & 0.31 \\
\hline C11 & EEE-FTH101XAP & 1 & $\$$ & 0.53 & $\$$ & 0.53 \\
\hline $\mathrm{C} 7$ & GCM21BR72A104KA37L & \multirow{4}{*}{4} & \multirow{4}{*}{$\$$} & \multirow{4}{*}{0.08} & \multirow{4}{*}{$\$$} & \multirow{4}{*}{0.30} \\
\hline C1 & GCM21BR72A104KA37L & & & & & \\
\hline C36 & GCM21BR72A104KA37L & & & & & \\
\hline C37 & GCM21BR72A104KA37L & & & & & \\
\hline C8 & GRM1885C1H101JA01D & 1 & $\$$ & 0.03 & $\$$ & 0.03 \\
\hline C5 & GRM1885C1H151JA01D & 1 & $\$$ & 0.05 & $\$$ & 0.05 \\
\hline C6 & GRM1885C1H331JA01D & 1 & $\$$ & 0.05 & $\$$ & 0.05 \\
\hline C19 & GRM219R7YA105KA12D & \multirow{3}{*}{3} & \multirow{3}{*}{$\$$} & \multirow{3}{*}{0.12} & \multirow{3}{*}{$\$$} & \\
\hline $\mathrm{C} 2$ & GRM219R7YA105KA12D & & & & & 0.35 \\
\hline C33 & GRM219R7YA105KA12D & & & & & \\
\hline & & & & & & \\
\hline & & & & & & \\
\hline
\end{tabular}




\begin{tabular}{|c|c|c|c|c|c|c|}
\hline C15 & GRM21BR72A103KA011 & & & & & \\
\hline C16 & GRM21BR72A103KA01L & & & & & \\
\hline C17 & GRM21BR72A103KA01L & & & & & \\
\hline C18 & GRM21BR72A103KA01L & & & & & \\
\hline $\mathrm{C} 20$ & GRM21BR72A103KA01L & 8 & $\$$ & 0.04 & $\$$ & 0.32 \\
\hline $\mathrm{C} 21$ & GRM21BR72A103KA01L & & & & & \\
\hline C34 & GRM21BR72A103KA01L & & & & & \\
\hline C35 & GRM21BR72A103KA01L & & & & & \\
\hline C10 & GRM32ER72A105MA01L & & & & & \\
\hline C12 & GRM32ER72A105MA01L & & & & & \\
\hline C22 & GRM32ER72A105MA01L & & & & & \\
\hline $\mathrm{C} 23$ & GRM32ER72A105MA01L & 7 & $\$$ & 0.38 & $\$$ & 2.66 \\
\hline C24 & GRM32ER72A105MA01L & & & & & \\
\hline C29 & GRM32ER72A105MA01L & & & & & \\
\hline $\mathrm{C} 30$ & GRM32ER72A105MA01L & & & & & \\
\hline PAD5 & H9004-01 & & & & & \\
\hline PAD6 & H9004-01 & & & & & \\
\hline PAD7 & H9004-01 & 4 & $\$$ & 0.33 & $\$$ & 1.30 \\
\hline PAD8 & H9004-01 & & & & & \\
\hline Q2/Q3 & IPB020NE7N3 G & 2 & $\$$ & 3.90 & $\$$ & 7.80 \\
\hline ר & $1 \mathrm{M} 4040 \mathrm{OYM}-25-\mathrm{TR}$ & 1 & $\$$ & 0.32 & $\$$ & 0.32 \\
\hline $\mathrm{U} 2$ & LT1716CS5\#TRMPBF & & & & & \\
\hline $\mathrm{U} 4$ & LT1716CS5\#TRMPBF & 2 & $\$$ & 2.50 & $\$$ & 5.00 \\
\hline $\mathrm{U} 1$ & $\begin{array}{l}\text { LTC3814IFE or } \\
\text { LTC1814EFE }\end{array}$ & 1 & $\$$ & 7.18 & $\$$ & 7.18 \\
\hline $\mathrm{R} 7$ & MCR03ERTF3003 & 1 & $\$$ & 0.02 & $\$$ & 0.02 \\
\hline R16 & MCR03ERTJ000 & & & & & 001 \\
\hline $\mathrm{R} 22$ & MCR03ERTJ000 & 2 & $\$$ & 0.01 & $\$$ & \\
\hline R15 & MCR10ERTF1001 & 1 & $\$$ & 0.02 & $\$$ & 0.02 \\
\hline R18 & MCR10ERTF1002 & & $\$$ & 002 & $\$$ & 004 \\
\hline R21 & MCR10ERTF1002 & 2 & $\$$ & & & \\
\hline$\frac{\mathrm{R} 8}{\mathrm{~B} 19}$ & MCR10ERTF1003 & 2 & $\$$ & 0.02 & $\$$ & 0.04 \\
\hline $\begin{array}{l}\text { R19 } \\
\text { R3 }\end{array}$ & $\begin{array}{l}\text { MCR10ERTF1003 } \\
\text { MCR10ERTF4990 }\end{array}$ & 1 & $\$$ & 002 & $\$$ & 002 \\
\hline R9 & MCR10ERTF4991 & $?$ & 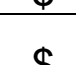 & 000 & 4 & 001 \\
\hline R14 & MCR10ERTF4991 & 2 & $\$$ & 0.02 & $\$$ & 0.04 \\
\hline R25 & MCR10ERTF49R9 & 1 & $\$$ & 0.02 & $\$$ & 0.02 \\
\hline R5 & MCR10ERTF6491 & 1 & $\$$ & 0.02 & $\$$ & 0.02 \\
\hline R4 & MCR10ERTF7872 & & & & & \\
\hline R17 & MCR10ERTF7872 & 3 & $\$$ & 0.02 & $\$$ & 0.06 \\
\hline R20 & MCR10ERTF7872 & & & & & \\
\hline
\end{tabular}




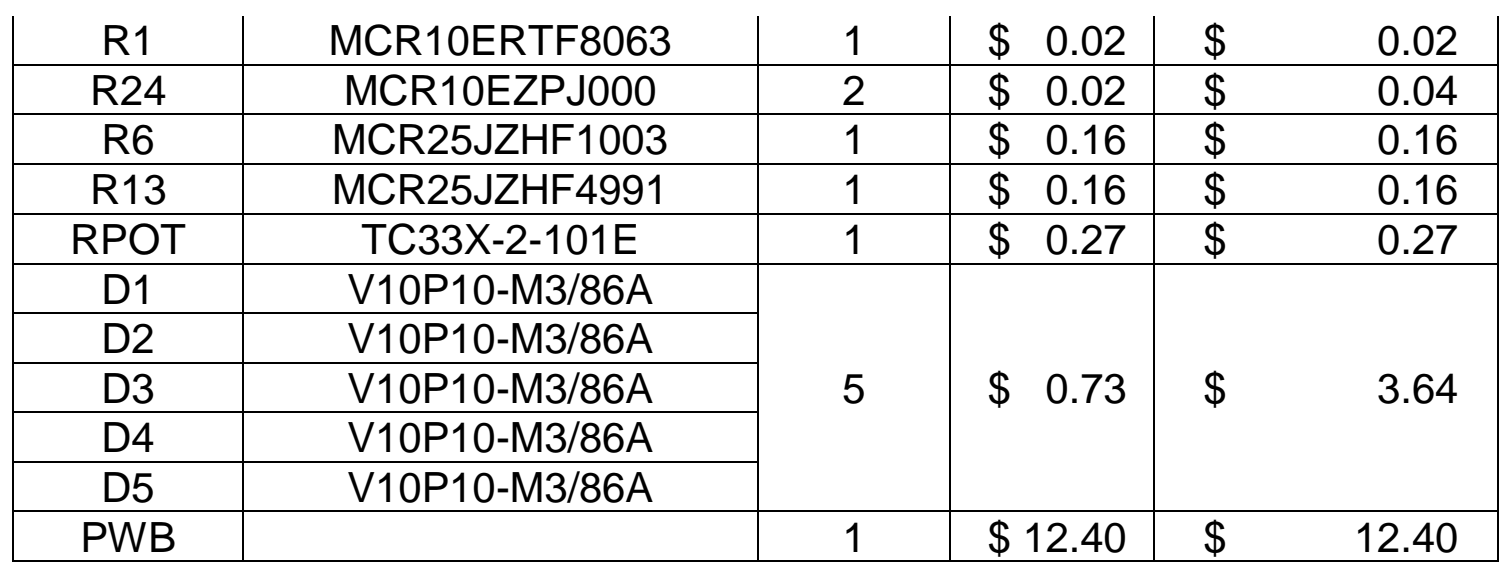

\begin{tabular}{|cc|}
\hline $\begin{array}{c}\text { Total Converter } \\
\text { Cost }\end{array}$ \\
\hline$\$$ & 61.57 \\
\hline
\end{tabular}




\section{APPENDIX D}

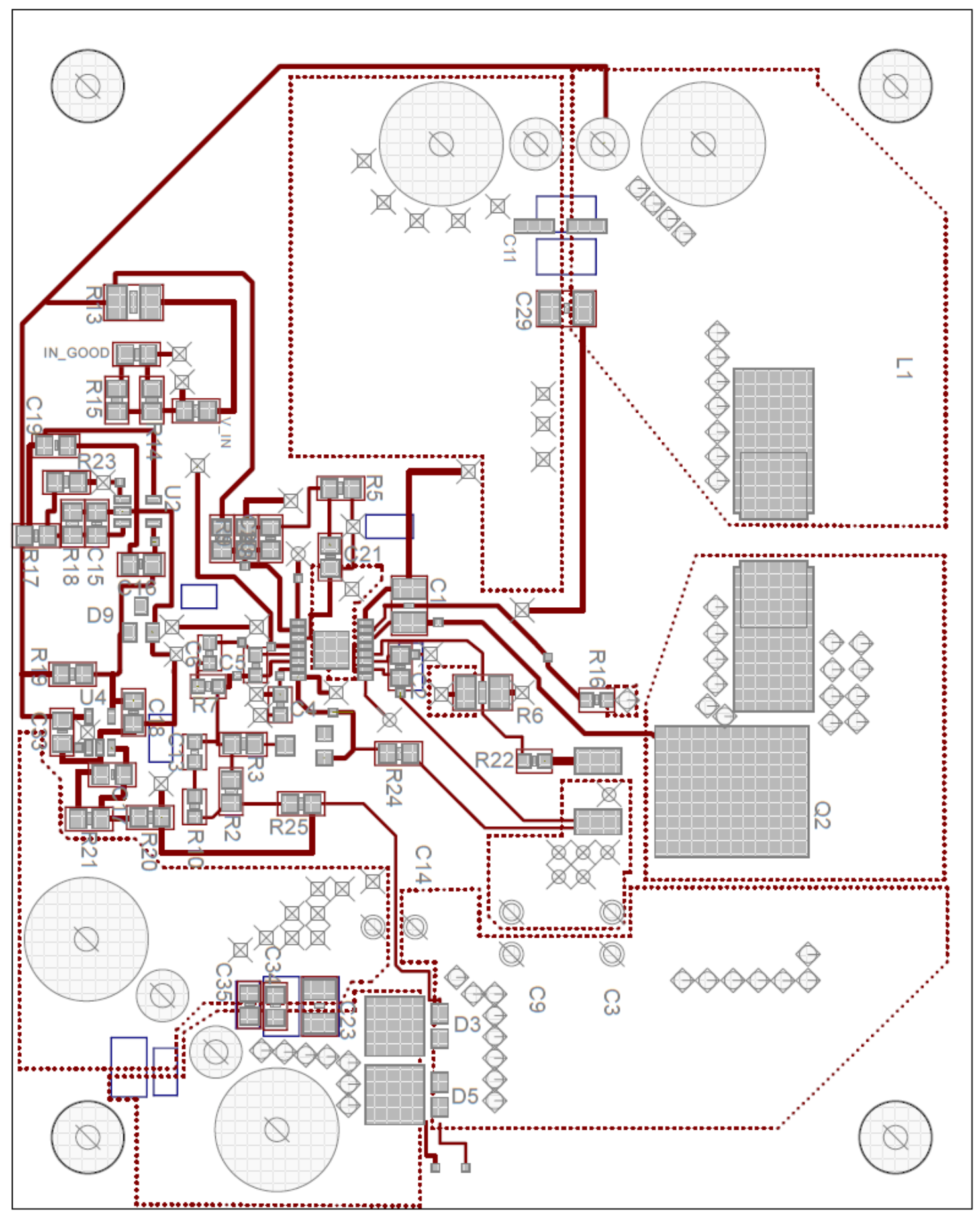




\section{APPENDIX E}

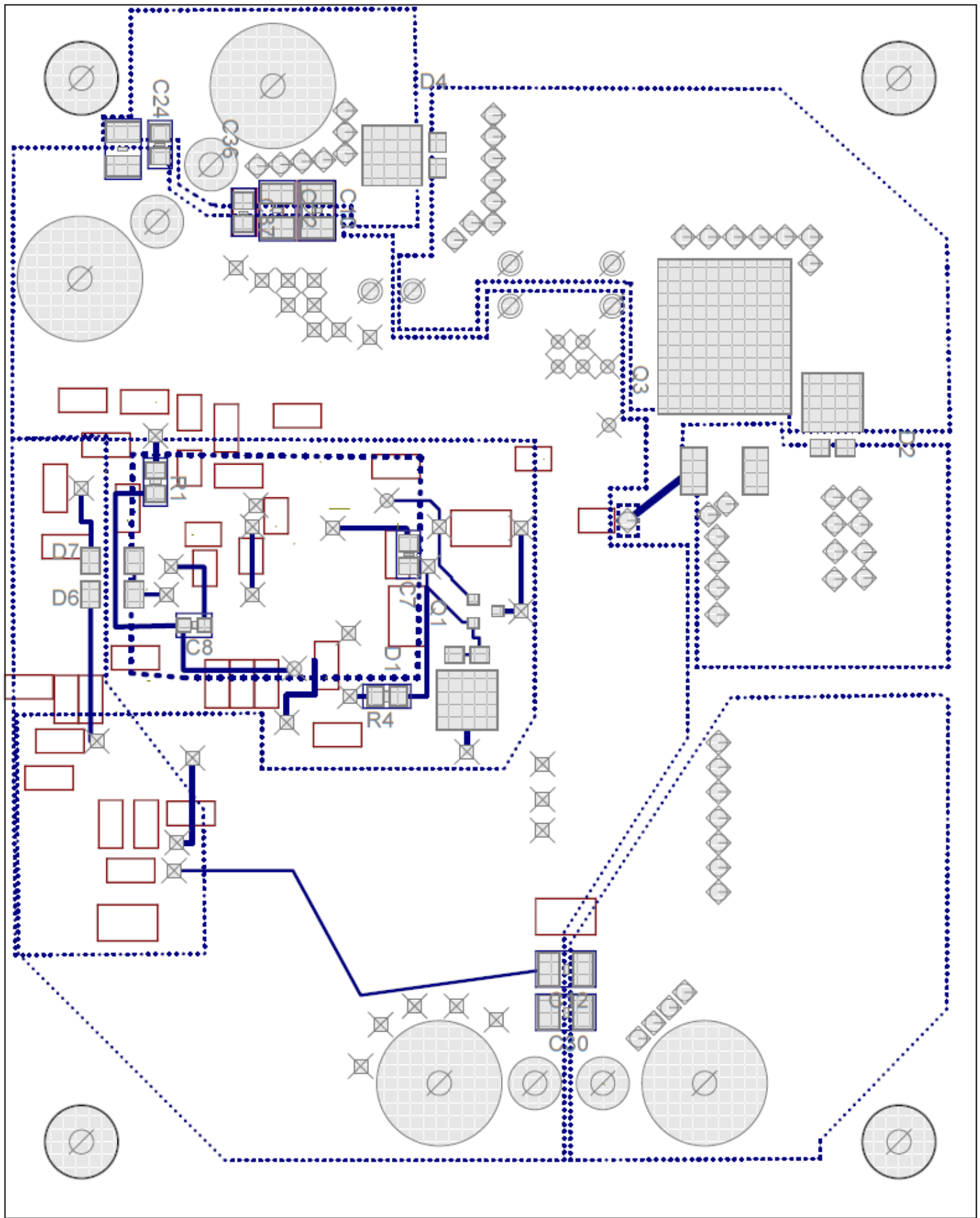

